\title{
Cloud chamber experiments on the origin of ice crystal complexity in cirrus clouds
}

\author{
Martin Schnaiter ${ }^{1}$, Emma Järvinen ${ }^{1}$, Paul Vochezer ${ }^{1}$, Ahmed Abdelmonem ${ }^{1}$, Robert Wagner ${ }^{1}$, Olivier Jourdan ${ }^{2}$, \\ Guillaume Mioche $^{2}$, Valery N. Shcherbakov ${ }^{2}$, Carl G. Schmitt ${ }^{3}$, Ugo Tricoli ${ }^{4}$, Zbigniew Ulanowski ${ }^{5}$, and \\ Andrew J. Heymsfield ${ }^{3}$ \\ ${ }^{1}$ Institute of Meteorology and Climate Research - Atmospheric Aerosol Research, \\ Karlsruhe Institute of Technology (KIT), Karlsruhe, Germany \\ ${ }^{2}$ Laboratoire de Métérologie et Physique (LaMP), Clermont-Ferrand, France \\ ${ }^{3}$ National Center for Atmospheric Research (NCAR), Boulder, Colorado, USA \\ ${ }^{4}$ Institute of Environmental Physics, University of Heidelberg, Heidelberg, Germany \\ ${ }^{5}$ Centre for Atmospheric and Instrumentation Research, University of Hertfordshire, Hatfield, UK
}

Correspondence to: Martin Schnaiter (martin.schnaiter@kit.edu)

Received: 22 October 2015 - Published in Atmos. Chem. Phys. Discuss.: 4 November 2015

Revised: 8 April 2016 - Accepted: 12 April 2016 - Published: 25 April 2016

\begin{abstract}
This study reports on the origin of small-scale ice crystal complexity and its influence on the angular light scattering properties of cirrus clouds. Cloud simulation experiments were conducted at the AIDA (Aerosol Interactions and Dynamics in the Atmosphere) cloud chamber of the Karlsruhe Institute of Technology (KIT). A new experimental procedure was applied to grow and sublimate ice particles at defined super- and subsaturated ice conditions and for temperatures in the -40 to $-60^{\circ} \mathrm{C}$ range. The experiments were performed for ice clouds generated via homogeneous and heterogeneous initial nucleation. Small-scale ice crystal complexity was deduced from measurements of spatially resolved single particle light scattering patterns by the latest version of the Small Ice Detector (SID-3). It was found that a high crystal complexity dominates the microphysics of the simulated clouds and the degree of this complexity is dependent on the available water vapor during the crystal growth. Indications were found that the small-scale crystal complexity is influenced by unfrozen $\mathrm{H}_{2} \mathrm{SO}_{4} / \mathrm{H}_{2} \mathrm{O}$ residuals in the case of homogeneous initial ice nucleation. Angular light scattering functions of the simulated ice clouds were measured by the two currently available airborne polar nephelometers: the polar nephelometer (PN) probe of Laboratoire de Métérologie et Physique (LaMP) and the Particle Habit Imaging and Polar Scattering (PHIPS-HALO) probe of KIT. The measured scattering functions are featureless and flat in
\end{abstract}

the side and backward scattering directions. It was found that these functions have a rather low sensitivity to the small-scale crystal complexity for ice clouds that were grown under typical atmospheric conditions. These results have implications for the microphysical properties of cirrus clouds and for the radiative transfer through these clouds.

\section{Introduction}

Cirrus clouds are situated in the cold upper troposphere at temperatures typically below $-35^{\circ} \mathrm{C}$, and, therefore, they are completely composed of ice particles (Guignard et al., 2012; Baran et al., 2012). With their persistent coverage of about $30 \%$ in the midlatitudes and up to $70 \%$ in the tropics, these clouds are an important component of the Earth's energy balance (Guignard et al., 2012). The underlying net radiative effect is expressed by the difference between a cooling effect due to the reflection of incoming shortwave solar radiation (albedo effect) and a warming effect by the absorption of outgoing long-wave terrestrial radiation (greenhouse effect). Both effects depend on the macroscopic properties of the clouds, like the ice water content (IWC) or the cloud optical thickness $\tau$, as well as the size, shape, and crystal complexity of the constituent ice particles (Zhang et al., 1999). 
The mean global net radiative effect of cirrus clouds is highly uncertain, because their solar albedo cannot easily be quantified due to the unknown scattering properties of the complex-shaped ice particles. The crystal complexity can alter the local net radiative effect of a cirrus cloud (with otherwise fixed macroscopic parameters) from -40 to $+20 \mathrm{~W} \mathrm{~m}^{-2}$ (Zhang et al., 1999), though the global effect by cirrus clouds is much less. Airborne in situ measurements of the microphysical properties of cirrus clouds have revealed an increasing wealth of different sizes, shapes, and crystal complexity (see, e.g., Baran, 2012, for an overview). This clearly emphasizes that more specific studies are necessary on the link between the ice particle microphysical complexity and the macroscopic cloud radiative properties.

For a better assessment of the cirrus radiative effects, single particle light scattering models for different ice particle shapes and degree of crystal complexity have been developed over the last 2 decades (Baran, 2009; Yang et al., 2015). These calculations have been stimulated by the remote sensing community, which need realistic ice particle light scattering properties to improve their retrieval algorithms. The cirrus ice crystal model used in these algorithms has successively been extended in order to cover the increasing ice cloud remote sensing observations like spectral reflection, polarization, and depolarization. With these new observations, there is now increasing evidence that highly complex ice particles (irregular particles or crystals with rough surfaces) are necessary to get a consistent interpretation of the combined satellite observations (Baran et al., 2003; Baran and Francis, 2004; Baum et al., 2011; van Diedenhoven et al., 2013; Baran et al., 2014b; Liu et al., 2014; Cole et al., 2014). The angular scattering function of such ice particles is calculated to be featureless with a flat trend at backscattering angles, so that the ice features observed in the scattering function of pristine ice particles, i.e., the 22 and $46^{\circ}$ halos as well as the ice bow at backscattering angles, are smoothed out. Field et al. (2003) analyzed SID-2 single particle scattering patterns in order to draw conclusions on the scattering phase function of cirrus ice crystals. They found no evidence for $22^{\circ}$ halos in their data set of midlatitude cirrus. The featureless and flat scattering functions result in relatively low asymmetry parameters, $g$, below 0.8 for these particles and between 0.75 and 0.78 for retrieved $g$ values inferred from recent remote sensing polarization observations (van Diedenhoven et al., 2013; Cole et al., 2014).

In situ measurements of the angular light scattering function in midlatitude cirrus clouds (Gayet et al., 1998, 2004; Febvre et al., 2009) as well as Arctic mid-level ice (Lampert et al., 2009) and mixed-phase clouds (Jourdan et al., 2010) by the polar nephelometer (PN; Gayet et al., 1997) revealed a low asymmetry parameter in the range from 0.76 to 0.79 , indicating ice particles with deeply roughened surfaces. Ulanowski et al. (2006) measured the angular light scattering function of smooth and roughened ice analogue crystals in the laboratory. They deduced very low asymmetry parame- ters of 0.63 for rough hexagonal rosette crystals, which differ significantly from the parameters around 0.8 recorded for smooth rosettes.

Over the last few years, an increasing number of studies have been published that apply the environmental electron microscopy technique to investigate the surface properties of growing and sublimating ice particles over a wide range of temperatures (Pfalzgraff et al., 2010; Neshyba et al., 2013; Ulanowski et al., 2014; Magee et al., 2014). The common observation of these studies is a prevalent mesoscopic roughness topography of the ice crystal surfaces on the scale of 1-20 $\mu \mathrm{m}$. Neshyba et al. (2013) derived a roughness parametrization from their micrographs and applied a raytracing model to calculate the expected consequences for the angular light scattering function. They calculated a significant reduction of the asymmetry parameter of about 0.04 to 0.06 due to the derived surface roughness. Although these investigations indicate a prominent mesoscale surface texture of the ice crystals with the ice saturation ratio as an important driving factor, the relevance of these findings for real atmospheric ice particles is still under debate.

As already mentioned, the uncertainties in assessing the radiative effect by cirrus clouds are due to the uncertainties of many macroscopic as well as microscopic cloud properties like IWC, the vertical structure of the ice particle size and shape distributions, the amplitude and distribution of the small ice mode, etc. (Mitchell et al., 2008; Yang et al., 2012; Baran et al., 2014a). However, if ice crystal surface roughness is a prevalent feature of atmospheric ice particles, the reduced asymmetry parameters of these particles has significant consequences for the cloud radiative effect, as it was recently shown in a climate modeling study by Yi et al. (2013). They used the National Center for Atmospheric Research Community Atmosphere Model (CAM, version 5.1) and calculated the global net radiative effects of clouds consisting of smooth and severely roughened ice particles. A globalaveraged difference of $-1.46 \mathrm{~W} \mathrm{~m}^{-2}$ was calculated between the runs with smooth and roughened ice particles, indicating that ice particle surface roughness has the potential to force the energy balance in a similar magnitude as the greenhouse gases but opposite in sign. However, the underlying assumption that all atmospheric ice particles have a similar degree of crystal complexity and, therefore, a similar low asymmetry parameter is highly questionable.

In the present study, the development of crystal complexity during cirrus ice particle formation and growth was investigated in controlled experiments at the cloud simulation chamber AIDA (Aerosol Interactions and Dynamics in the Atmosphere). A new experimental procedure was applied to grow and sublimate ice particles at defined super- and subsaturated ice conditions and for temperatures in the -40 to $-60^{\circ} \mathrm{C}$ range. In these experiments the following questions were addressed. 
i. What is the role of the thermodynamic conditions prevailing during ice particle growth for the crystal complexity?

ii. Does the ice nucleation type, i.e., heterogeneous or homogeneous, have an influence on the ice crystal complexity?

iii. What is the impact of ice crystal complexity on the angular light scattering function and the asymmetry parameter $g$ ?

The crystal complexity was deduced from single particle measurements by the latest version of the Small Ice Detector (SID-3), which has been recently applied in an aircraft field study by Ulanowski et al. (2014).

The SID-3 method to deduce single particle complexity is described in Sect. 2.1 followed by an introduction to the AIDA cloud chamber instrumentation and the experimental procedure in Sect. 2.2. It was found that ice crystal complexity is frequently observed in the simulated ice clouds and the degree of this complexity is dependent on the available water vapor during the crystal growth. A parametrization was developed to link the crystal complexity to the available water vapor. This parametrization as well as the link between the angular light scattering properties and ice crystal complexity are presented in Sect. 3. The atmospheric relevance of the results is discussed in Sect. 4 and the final conclusions are drawn in Sect. 5.

\section{Methods}

\subsection{Quantification of ice crystal complexity and surface roughness}

\subsubsection{Measurement of high-resolution angular light scattering patterns}

Crystal complexity of individual small ice particles is measured using the Small Ice Particle Detector Mk. 3 (SID-3). To differentiate single crystal complexity, which is the subject of the present study, to the complexity that is induced by crystal aggregation, we henceforth use the term "small-scale complexity", which is often referred to as surface roughness. While large-scale complexity or crystal aggregation can easily be observed by high-resolution imaging (e.g., Schmitt and Heymsfield, 2014), the characterization of small-scale complexity needs a different approach, like the detection of high-resolution scattering patterns described here. Smallscale complexity, therefore, comprises all surface distortions on a single ice particle (surface roughness on a variety of scales, polycrystallinity, and (stepped) hollowness) that results in the formation of speckles in coherent light scattering. The analysis of these spatial fluctuations in the scattered intensity of individual particles is the fundamental method of measuring single particle complexity with SID-3 (Ulanowski et al., 2014).

SID-3 is the latest version of a suite of airborne single particle cloud probes that were developed by the University of Hertfordshire, UK. The derivation of ice particle complexity from SID-3 measurements is possible, since the basic concept of the SID instruments differ from other airborne single particle scattering probes. While these probes measure the total scattered light intensity in forward direction, the SID instruments additionally quantify the spatial distribution of the forward scattered light at different resolution levels. The first version of the instrument uses six azimuthally arranged detectors and was primarily designed to discriminate between super-cooled water droplets and ice particles (Hirst et al., 2001). The second versions, named SID- 2 and SID-2H, were designed to detect azimuthal light scattering patterns with 24 and 28 detectors, respectively (Cotton et al., 2010; Johnson et al., 2014). Finally, SID-3 uses an intensified charged coupled device camera (ICCD) to acquire two-dimensional (2D) forward light scattering patterns with an angular resolution of better than $0.1^{\circ}$. Details of the instrument set up and data acquisition can be found in Ulanowski et al. (2014) and Vochezer et al. (2016). Here, we want to briefly highlight those features of SID-3 that are important for the ice crystal complexity measurements.

In the SID-3 probe individual particles pass a $532 \mathrm{~nm}$, $30 \mathrm{~mW}$ laser beam. From these particles, 2-D light scattering patterns are acquired using a $780 \times 582$ pixels ICCD (Photek Ltd, UK) with a maximum repetition rate of $30 \mathrm{~Hz}$. Although images can be stored as 12 bit TIFF files, we set SID- 3 to store the patterns as 8 bit grey-scale JPEG files to be consistent with the laboratory and field studies by Ulanowski et al. (2014) and Vochezer et al. (2016). Image brightness can be adjusted by changing the intensifier gain of the ICCD. For the chamber experiments, we have chosen gains of 175 or 180 in order to get a maximum of analyzable scattering patterns (neither underexposed nor saturated) for the particle size range from about 3 to $30 \mu \mathrm{m}$.

In the case of the SID-3 instrument, the (usable) polar angular range covered by the annulus-shaped main detector aperture is 7 to $23^{\circ}$ relative to the forward scattering direction. Representative examples of 2-D scattering patterns of single small ice particles that were nucleated and grown in our cloud chamber experiments are given in Fig. 1. Note that for pristine hexagonal ice columns the scattering patterns (given in Fig. 1a, b) clearly show the $22^{\circ}$ halo refraction peaks on the intense diffraction arc that corresponds to the $c$ axis of the crystals. In the case of roughened or distorted columnar ice crystals (as shown in Fig. 1c, d), speckles emerge in the angular regions outside the diffraction arcs indicating a more diffuse spatial scattering behavior of the corresponding crystals. A description of how the scattering patterns are analyzed to infer a measure of the crystal complexity is given in Sect. 2.1.2. Details on the experimental proce- 


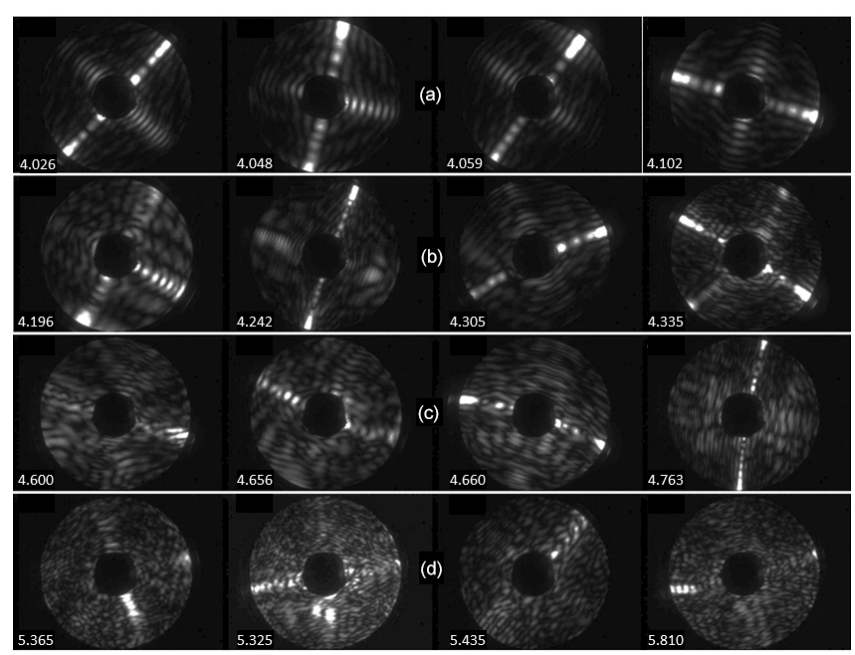

Figure 1. Representative examples of 2-D light scattering patterns of individual small columnar ice particles generated in re-growth cloud chamber experiments at $-50^{\circ} \mathrm{C}$. The patterns are labeled by the energy feature parameter $k_{\mathrm{e}}$ (lower left corner). The patterns are arranged according to increasing $k_{\mathrm{e}}$ from left to right and from panels (a) to (d). Particle fractions that have a significant degree of small-scale complexity are deduced by setting a threshold value of $k_{\mathrm{e}}^{\mathrm{thr}}=4.6$ and classifying all particles equal and above as complex.

dures to grow ice crystals with different degrees of complexity are presented in Sect. 2.2.2.

In addition to the 2-D scattering patterns, the triggering system of SID-3 stores scattering intensity data of all particles that have passed the sensing area of the instrument, i.e., also for those particles that were detected while the ICCD was still busy with the image processing of a previous particle. The maximum acquisition rate for trigger intensity data is $11 \mathrm{kHz}$. This feature allows us to (i) calibrate the trigger detector by a set of scattering patterns from water droplets and (ii) generate statistically well-defined particle size distributions based on the trigger intensity measurements. In the case of SID-3, the trigger intensity measurements are performed under a relatively narrow solid angle around the $50^{\circ}$ direction with respect to the forward direction.Therefore, the measurement is biased by the particle orientation in the case of aspherical ice particles. For this reason, the trigger intensity measurements from the Particle Phase Discriminator (PPD$2 \mathrm{~K}$ ), the laboratory version of SID-3, was used in the present study to determine the particle size distribution of the chamber ice clouds. PPD-2K measures the light scattering intensity of each individual particle over the annulus-shaped main detector aperture which is less biased by particle orientation. In addition, PPD-2K has a specifically designed inlet nozzle that focusses the sampled particles to the sensitive area of the instrument which results in better counting statistics compared to SID-3. Details on the PPD-2K and the size calibration procedure can also be found in Vochezer et al. (2016).

\subsubsection{Scattering pattern analysis}

For the analysis of the 2-D scattering patterns, a comprehensive image processing and analysis software was developed using the Vision Development Module of the LabView ${ }^{\text {TM }}$ (National Instruments Inc., USA) package. A detailed description of the main analysis steps per scattering pattern can be found in Vochezer et al. (2016). These steps comprise

- the computation of the polar integrated azimuthal intensity profile for droplet/ice discrimination

- a Mie fit procedure of the azimuthally integrated polar intensity profile in the case of spherical particles to determine the droplet diameter

- a discrete fast Fourier transformation of the polar intensity profile for the shape classification of ice particles

- a speckle pattern texture analysis to deduce small-scale ice crystal complexity.

While the first three steps are explained in detail in Vochezer et al. (2016), the final speckle pattern analysis step is described in the following.

The crystal complexity analysis relies on the grey-level cooccurrence matrix (GLCM) method described in $\mathrm{Lu}$ et al. (2006). This method was originally developed in the context of quality control of surface treatment processes, and Ulanowski et al. (2010) transferred it for the first time to the analysis of SID-3 ice crystal scattering patterns. The GLCM method was further applied in a first study on ice crystal complexity of simulated cirrus clouds generated in the AIDA cloud chamber (Schnaiter et al., 2011) and in the analysis of SID-3 data of atmospheric ice particles by Ulanowski et al. (2014).

The GLCM represents a frequency matrix describing how often pairs of grey levels occur in a texture image for pixels separated by a certain distance $\Delta d$ and along a certain direction. In case of the 8 bit grey-level scattering patterns generated by SID-3, the GLCM has a size of $128 \times 128$ elements, where each element $p(i, j)$ represents a specific pair of grey-level values given by the two matrix indices $i, j$. The values of the individual elements give the total number of the corresponding grey-level pairs that were found when the algorithm is moving pixel-wise across the scattering pattern. Illustrations of this procedure can be found in Figs. 3 and 4 of Lu et al. (2006). Speckle pattern texture features can then be extracted from the GLCM, like the energy or uniformity feature $E$ that represents the sum of the squared elements in the GLCM

$E=\sum_{i=0}^{m-1} \sum_{j=0}^{m-1} p(i, j)^{2}$.

Routinely, the five features contrast, correlation, energy, entropy, and homogeneity are computed (see Haralick et al., 
1973, for details). In addition to these texture features, a "combined roughness measure" as defined by Ulanowski et al. (2014) as well as the normalized energy feature parameter $k_{\mathrm{e}}$ are computed by the image processing software. The former is a combination of $E$ with measures of the image brightness distribution which (i) has a clear correlation with the subjective particle surface roughness and (ii) is less sensitive to image brightness variations. The latter was introduced by Lu et al. (2006). They investigated the correlation of the GLCM features to the physical roughness for laser scattering patterns $(\lambda=0.66 \mu \mathrm{m})$ from standard grinding specimens with average surface roughness profile parameters $R_{\mathrm{a}}$ in the range from 0.05 to $1.6 \mu \mathrm{m}$. The energy feature $E$ was found to have the best correlation to the physical surface roughness. Moreover, Lu et al. (2006) investigated the robustness of $E$ for variances in the configuration of the measurement, e.g., laser power stability, and suggested an exponential fit to the energy feature vs. pixel distance function $E(\Delta d)$ as the most robust roughness measure. The energy feature parameter $k_{\mathrm{e}}$ then represents the coefficient of this exponential fit to the combined $E(\Delta d)$ curves that were calculated from the GLCM for the four distinct directions 0, 45, 90, and $135^{\circ}$. In the present analysis algorithm, $k_{\mathrm{e}}$ is deduced based on the energy feature curves that are calculated for the first three directions. Each of the three curves covers the $\Delta d$ range from 1 to 31 . So, a total number of $3 \times 30=90$ GLCM are calculated and analyzed per scattering pattern.

According to Lu et al. (2006), the energy feature parameter $k_{\mathrm{e}}$ has "a good relationship with the surface roughness; is more robust to the variances of the setup configuration, the position, and the orientation of the surface to be measured; and is the best feature parameter to characterize the surface roughness". They plotted the dependence of $k_{\mathrm{e}}$ on the physical surface roughness profile parameter $R_{\mathrm{a}}$ and found that for the $R_{\mathrm{a}}$ value range from 0.1 to about $0.4 \mu \mathrm{m}$ the $k_{\mathrm{e}}$ values increase from 4 to 5.8 , respectively. Moreover, $k_{\mathrm{e}}$ started to saturate at a value around 6 for $R_{\mathrm{a}}$ values larger than the laser wavelength. The robustness of $k_{\mathrm{e}}$ for the SID-3 optical system and for variances in laser power was also investigated in the present work by using analogue ice particles residing on glass plates as test objects (see Appendix A for details). The result of this test (given in Table A1) shows that $k_{\mathrm{e}}$ varies by less than $1 \%$ over a broad image brightness range. Further, discrete dipole approximation (DDA) light scattering calculations of deformed spherical ice particles were conducted for different deformation degrees in order to determine a relationship between the $k_{\mathrm{e}}$ value and the particle surface modifications. Details of this modeling work can be found in Appendix B. In summary, these tests show that (i) $k_{\mathrm{e}}$ is the most robust feature parameter to characterize small-scale crystal complexity with SID-3 and (ii) there is a correlation between the optical feature $k_{\mathrm{e}}$ and the physical surface distortion in the range from 0.1 to about $1 \mu \mathrm{m}$ when $k_{\mathrm{e}}$ starts to saturate. The analysis and interpretation of the SID-3 data therefore rely on $k_{\mathrm{e}}$ as the primary measure for small-scale ice crystal complexity.

For this work the above listed scattering pattern analysis steps were restricted to images within a narrow mean brightness (grey level) range between 10 and 25 . In this way we could minimize remaining image brightness biases on the GLCM analysis results. For this brightness range the relative standard deviation in $k_{\mathrm{e}}$ is only $0.7 \%$ and the fraction of saturated pixels per pattern is always below $1 \%$ even for the brightest images (see Appendix A).

\subsection{Cloud chamber simulation experiments}

The ice crystal growth experiments were conducted in the aerosol and cloud simulation chamber AIDA of the Karlsruhe Institute of Technology. AIDA can be operated as an expansion chamber to simulate the atmospheric conditions in ascending cloud parcels in the temperature range down to $-90^{\circ} \mathrm{C}$. The general experimental procedure applied in these cloud expansion experiments has been described in several publications (e.g., Möhler et al., 2005a; Wagner et al., 2006, 2015; Schnaiter et al., 2012). In the present study, the chamber was used to simulate ice clouds in the cirrus temperature regime. A novel experimental procedure was developed to modify the ice crystal surface properties and their degree of small-scale complexity through growth and sublimation periods at defined super- and subsaturated ice conditions. This method is different from the standard expansion procedure (see, e.g., Möhler et al., 2005a) and is therefore described in more detail in Sect. 2.2.2. In the following section, the chamber instrumentation is introduced that was applied in the experiments.

\subsubsection{Instrumentation}

We used the same instrument configuration as in the study of Schnaiter et al. (2012) with additional airborne cloud particle probes; the PN (Gayet et al., 1997), the Particle Habit Imaging and Polar Scattering probe (PHIPS) as well as a Formvar replicator very similar to the one used in Miloshevich and Heymsfield (1997). A scheme of the basic experimental setup is shown in Fig. 5 of Schnaiter et al. (2012).

PHIPS-HALO is a novel airborne cloud probe that has been developed and certified for the operation on-board the new German research aircraft HALO (High Altitude and LOng Range). PHIPS-HALO is a combination of a stereoscopic imager and a polar nephelometer to acquire (i) micrographs of individual ice particles from two directions at an optical resolution of about $2.5 \mu \mathrm{m}$ and (ii) the polar scattering function of the same particle in the angular range from 1 to $170^{\circ}$. Details on the basic instrument concept and measurement methods can be found in Schön et al. (2011) and Abdelmonem et al. (2011) for the prototype versions and in Abdelmonem et al. (2016) for the airborne version of the instrument. The PN is an approved airborne instrument that 
measures, depending on the particle concentration, the polar scattering function of single particles or particle ensembles in the angular range from 3.5 to $169^{\circ}$ (Gayet et al., 1997; Crépel et al., 1997).

Ice particle replica were generated on $35 \mathrm{~mm}$ transparent plastic film strips that were precoated with polyvinyl formal (Formvar). Precoating was produced at room temperature by brushing one side of the plastic film with a solution of $5 \%$ Formvar in chloroform which results in a Formvar coating of about $100 \mu \mathrm{m}$. For the operation at the AIDA chamber the replicator was modified by a solvent dispensing system composed of $\sim 3 \mathrm{~m}$ teflon tubing and a syringe pump located outside the insulating housing of the chamber. In this way the softening of the Formvar coating by dispensing dichloromethane to the strip could be externally controlled. We used dichloromethane to soften the coating prior to the impaction of ice particles because of its low freezing point of $-95.1^{\circ} \mathrm{C}$ (Takahashi and Fukuta, 1988).

The airborne instruments PN, PHIPS-HALO, and SID-3 were located underneath the chamber within the temperaturecontrolled environment of AIDA. There, the instruments were installed into specific vacuum-sealed canisters in a strictly vertical orientation. These canisters have a $10 \mathrm{~mm}$ inner diameter stainless steel sampling tube that penetrates the chamber wall and projects into the chamber volume by about $0.2 \mathrm{~m}$. Each sampling tube is equipped with a hornshaped inlet to minimize sampling artifacts. Within the instrument canister, the sampling tube terminates about $10 \mathrm{~mm}$ in front of the sensing area of the instrument. Each canister is connected via a mass flow controller to the central vacuum system of the AIDA facility. By applying a mass flow of typically 50 standard liters per minute (standard $\mathrm{L} \mathrm{min}^{-1}$ ) cloud particles from the chamber volume can be sampled, accelerated to a speed of about $10 \mathrm{~m} \mathrm{~s}^{-1}$ in the sampling tube, and measured when exiting the tube close to the sensing area of the instrument. The ice particle replicator was installed in a similar canister as the other airborne instruments but was aspirated by only 20 standard $\mathrm{L} \mathrm{min}^{-1}$ in order to get a reasonable separation of the ice particle replica on the strip.

The PPD-2K has a vacuum-sealed detection cell, so there is no need for installing the instrument in a separate canister. The detection cell is equipped with a focusing particle nozzle that produces a confined particle beam with a cross section of $2.5 \mathrm{~mm}^{2}$. This cross section is small enough to completely fit into the flat rectangular laser beam cross section of the instrument. In this way, the forward scattering intensity of all sampled particles is detected and analyzed in terms of the equivalent optical particle diameter. Further details on the instrument design and the calibration procedure can be found in Vochezer et al. (2016).

Three different aerosol types were used in the cloud simulation experiments to initiate the ice formation: soot particles from a graphite spark generator (GFG 1000, PALAS) (Möhler et al., 2005b), Arizona Test Dust particles that were redispersed by a rotating brush generator (RGB 1000, PALAS) in conjunction with impaction stages to size select the $<2 \mu \mathrm{m}$ particles (Möhler et al., 2006), and aqueous sulfuric acid particles generated in a home-built $\mathrm{H}_{2} \mathrm{SO}_{4} / \mathrm{H}_{2} \mathrm{O}$ nucleation generator (Wagner et al., 2008).

Aerosol number concentrations prior to and during the cloud expansion runs were measured with a condensation particle counter (CPC3010, TSI). Several modifications have been applied to the CPC in order to ensure reliable operation during the cloud expansion runs, i.e., at differential pressures between the sampling line and the environment of more than $500 \mathrm{hPa}$ (Seifert et al., 2004). The aerosol number size distribution was measured with a scanning mobility particle sizer (SMPS, TSI) and an aerodynamic particle sizer (APS, TSI) (Möhler et al., 2006).

The presence of cloud particles inside the chamber is monitored by the laser light scattering and depolarization instrument SIMONE (Schnaiter et al., 2012). SIMONE measures scattered light from particles residing in the center of the chamber from near-forward $\left(2^{\circ}\right)$ and near-backward $\left(178^{\circ}\right)$ directions. The backscattered light is analyzed with respect to its polarization state which facilitates the derivation of the linear depolarization ratio $\delta_{1}$. Although SIMONE is routinely used to detect phase transitions in aerosol and cloud particle ensembles, it has recently also been used to investigate the microphysical properties of corona-producing ice clouds (Järvinen et al., 2014).

Water vapor measurements are conducted in two ways: in situ measurements by using a tunable diode laser (TDL) spectrometer (Ebert et al., 2005) to measure the interstitial water vapor mass and an extractive measurement for measuring the total (interstitial plus condensed) water mass. For the latter, we used a fast chilled-mirror frost-point hygrometer (MBW, model 373) that is located outside the insulating housing of AIDA and that is connected via a heated stainless steel tube to the chamber volume. The accuracy of the TDL and MBW measurements is $\pm 3 \%$. Further details on the water vapor measurements at AIDA can be found in Wagner et al. (2010) and Fahey et al. (2014).

\subsubsection{Growth and sublimation cycles}

A novel experimental procedure for the AIDA cloud chamber was developed in order to grow and sublimate ice particles at defined super- and subsaturated ice conditions. This procedure consists of the following main steps that are applied to the pre-cooled chamber. In the present work the experiments were conducted at initial chamber temperatures of -40 and $-50^{\circ} \mathrm{C}$.

1. Preparation: the chamber volume was cleaned by evacuation and flushing cycles. Then water vapor was added in excess to the evacuated cold chamber so that a thin ice coating was formed on the inner chamber wall. This humidification step was followed by refilling the chamber with dry synthetic air until a slight overpressure of about 1 mbar was reached. Homogeneous temperature and hu- 
midity conditions throughout the volume were ensured by operating the mixing ventilator of the chamber. After these preparation steps, a saturation ratio with respect to ice $S_{\text {ice }}$ of about $0.95 \pm 0.03$ and a background particle number concentration of $\sim 0.1 \mathrm{~cm}^{-3}$ were typically measured.

2. Aerosol addition: aerosol particles were generated by the respective aerosol generator (Sect. 2.2.1) and the aerosol flow was directed to the AIDA chamber. The AIDA particle number concentration was continuously monitored and the aerosol addition was stopped after the desired concentration had been reached. The aerosol size distribution was measured after a homogenization period of several minutes.

3. Initial cloud activation: a chamber expansion run was started by opening the valve to the vacuum pump. The suction capacity of the pump was controlled and was typically set to a value of either 60 or $80 \%$ of the full capacity, which is $250 \mathrm{~m}^{3} \mathrm{~h}^{-1}$. The start of the expansion marks the reference time of the experiment run and is given as time $0 \mathrm{~s}$ in Fig. 2. As a consequence of the decreasing pressure, the gas temperature decreases at nearly constant wall temperature (see Fig. 2a). The continuous increase in this temperature difference results in an increase of $S_{\text {ice }}$ from slightly subsaturated into supersaturated conditions (blue line in Fig. 2b). At a specific threshold supersaturation, which is dependent on the used aerosol type, ice starts to form. In our experiments, ice forms either by heterogeneous deposition nucleation on soot or mineral dust or by homogeneous freezing in the case of aqueous sulfuric acid. The ice formation onset is clearly marked by the strong increase in the SIMONE near-forward scattering signal (black line in Fig. 2d). After ice particles have been formed they grow on the expense of excess water vapor in the still supersaturated environment. Eventually, the size of the ice crystals is above the lower detection limit of $7 \mu \mathrm{m}$ of the PPD-2K instrument, so that they are counted (red line in Fig. 2d) and sized (color plot in Fig. 2c). At the same time the PHIPS-HALO instrument started to image ice particles as indicated by the mean equivalent sphere diameter shown in Fig. 2c. The constant offset between the two diameters plotted in Fig. $2 \mathrm{c}$ is due to the fact that ice particles have a lower differential scattering cross section compared to liquid water droplets in the angular range of the PPD-2K and, therefore, their size is underestimated by a factor of about 1.7 (Cotton et al., 2010). The increasing ice water content in the chamber is also nicely reflected by the increasing difference between the total water and interstitial water mass measurements (black and blue lines in Fig. 2b). Ice crystal growth continues as long as the expansion is maintained, e.g., until $310 \mathrm{~s}$ after start of the expansion in the example given in Fig. 2.
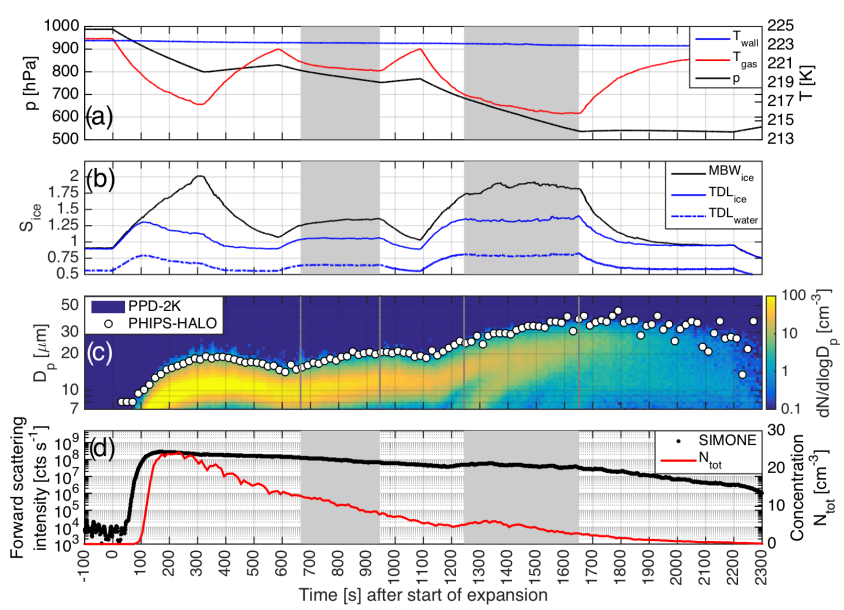

Figure 2. Example of a regrowth experiment conducted in the AIDA cloud chamber at an initial temperature of $-50^{\circ} \mathrm{C}$. The experimental procedure is specifically designed to grow and sublimate ice particles at defined super- and subsaturated ice conditions (solid blue line in panel b). Regrowth periods are indicated by the shaded areas. See text for details.

4. Sublimation period: as the initial growth of the ice particles depends on the specific ice nucleation properties of the aerosol used, the growth conditions in terms of supersaturation cannot be controlled. Therefore, a subsequent sublimation period was applied in order to remove the ice particle surface characteristics from the initial growth. For this purpose, a flow of dry synthetic air $\left(\sim 40 \mathrm{~m}^{3} \mathrm{~h}^{-1}\right)$ was fed into the chamber immediately after the expansion had been stopped, resulting in a compression of the chamber volume and, thus, in an increase of the gas temperature. Consequently, the ice saturation ratio $S_{\text {ice }}$ changed from supersaturated to subsaturated conditions due to the addition of dry air and the gas temperature increase (Fig. 2b). By controlling the compression air flow, a defined saturation ratio can be adjusted. In the experiment shown in Fig. 2, the saturation ratio was set to about 0.8 . As soon as the compression was applied, the ice particles started to sublimate as indicated by the decrease in the ice particle size (Fig. 2c). The ice particles were forced to sublimate for a period long enough to see a clear change of their shape and surface properties, but short enough not to completely sublimate them. A sufficient particle surface processing by sublimation is indicated by the observation of oval SID3 scattering patterns as shown in Fig. 3. A subsample of the scattering patterns acquired by SID-3 is displayed online by the instrument data acquisition software. A visual monitoring of these patterns is performed during the sublimation period in order to decide when the sublimation can be stopped.

5. Regrowth period: after the ice particle processing by sublimation had been completed, the regrowth of the ice 


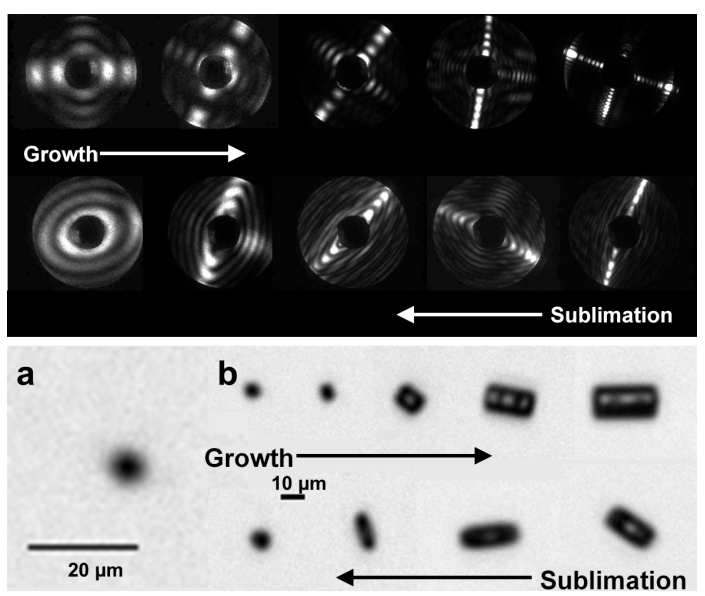

Figure 3. Evolution of SID-3 scattering patterns (upper panel) and PHIPS-HALO micrographs (series $b$ in the lower panel) of columnar ice particles collected during growth and sublimation periods in the $-40^{\circ} \mathrm{C}$ temperature range. Ice particle surface processing by sublimation is clearly visible by a roundening of the ice particle edges resulting in oval SID-3 scattering patterns. Note that SID-3 is capable to determine the particle shape for crystals with sizes of only 2 to $3 \mu \mathrm{m}$ (patterns on the left side of the upper panel) whereas the imaging method used in PHIPS-HALO cannot give a clear shape information for particles smaller than about $10 \mu \mathrm{m}$ (image a in the lower panel).

particles was started. For this purpose, the addition of compressing air was stopped followed by a controlled expansion of the chamber volume (e.g., at 580 s experiment time in Fig. 2). Since the basic idea of this experimental procedure was to control the ice particle grow speed, the regrowth should happen at a specific but nearly constant supersaturation (e.g., about 1.05 in case of the experiment shown in Fig. 2). For this purpose, the expansion was manually controlled by tuning the suction flow, while monitoring the saturation ratio measurement. Depending on the target supersaturation, suction flow tuning was applied either by using a mass flow controller (range up to $\sim 100 \mathrm{~m}^{3} \mathrm{~h}^{-1}$ ) or by changing the suction capacity of the pump. In this way, the regrowth of the ice particles was conducted at a nearly constant supersaturation over periods of at least $200 \mathrm{~s}$ (indicated by the shaded areas in Fig. 2). Several regrowth periods at different supersaturations can be performed within one ice cloud by repeating steps (4) and (5), provided that the ice particle number concentration, which is decreasing by sedimentation and sampling losses, is still above $\sim 5 \mathrm{~cm}^{-3}$.

\section{Results}

For the present work, a total of 45 sublimation and regrowth experiments have been selected from the AIDA campaign
HALO06 (preflight test campaign for the HALO aircraft; February 2011) and the AIDA Rough ICE particle campaigns RICE01 (November 2012), RICE02 (May 2013), and RICE03 (December 2014).

As the water vapor mixing ratio is frequently measured inside cirrus ice clouds, the basic idea of the regrowth experiments was to study the dependence of the small-scale ice particle complexity on the ice saturation ratio during the growth of the crystals. Therefore, the start and end times for each regrowth period were manually determined by examining the time curve of $S_{\text {ice }}$ (blue line in Fig. 2b) and identifying those periods where $S_{\text {ice }}$ showed a plateau (as indicated by the shaded areas in Fig. 2). The results of the single particle scattering pattern analysis were then statistically analyzed for these regrowth periods. As already mentioned, only scattering patterns within a narrow mean brightness (grey level) range from 10 to 25 were considered as valid patterns in this statistical analysis. Periods that had less than 100 valid scattering patterns were excluded from the study. For the same time periods, $S_{\text {ice }}$ was averaged to determine the mean ice saturation ratio, to which the ice crystals had been exposed during their regrowth.

The result of this analysis is shown in Fig. 4. Experiments that were started at initial temperatures of -40 and $-50^{\circ} \mathrm{C}$ are given as black and grey symbols, respectively. Note that the $1 \sigma$ error bars given for $S_{\text {ice }}$ represent the variations that are due to the manual control of the pumping speed in order to keep a constant saturation ratio. The median complexity parameter $\widetilde{k_{\mathrm{e}}}$ clearly increases with increasing supersaturation in the case of the $-50{ }^{\circ} \mathrm{C}$ experiments, and this trend is even steeper for the experiments that were conducted at an initial temperature of $-40^{\circ} \mathrm{C}$. As for a given supersaturation the available condensable water mass is increasing with increasing temperature, the ice particles will grow faster at warmer temperatures, and, consequently, more defects in the crystal lattice are expected. Ice particle habits and growth rates were measured in the laboratory by Bailey and Hallett (2004) for ice particles grown on thin glass wires over a broad temperature range from -20 to $-70^{\circ} \mathrm{C}$. They clearly observed faster growth rates with higher supersaturations and warmer temperatures. At $-50^{\circ} \mathrm{C}$ and for supersaturations of 20 and $40 \%$, growth rates of about 0.035 and $0.07 \mu \mathrm{m} \mathrm{s}^{-1}$, respectively, were measured for columnar ice particles. These results are in good agreement with the results of our own growth rate measurements by analyzing PHIPS-HALO images (see Appendix C). At $-40^{\circ} \mathrm{C}$ and for the same supersaturation range, Bailey and Hallett (2004) measured growth rates that were higher by a factor of at least two compared to the $-50^{\circ} \mathrm{C}$ results. The authors also report an increase in crystal complexity with increasing supersaturation, mainly represented by the development of hollowness and the formation of rosettes. At $-50^{\circ} \mathrm{C}$ these growth instabilities started to appear at an ice supersaturation around $20 \%$ which is in good agreement with the ice crystal habits that were found on the replicator strips (Fig. 5). At $-40^{\circ} \mathrm{C}$ a significant crystal 


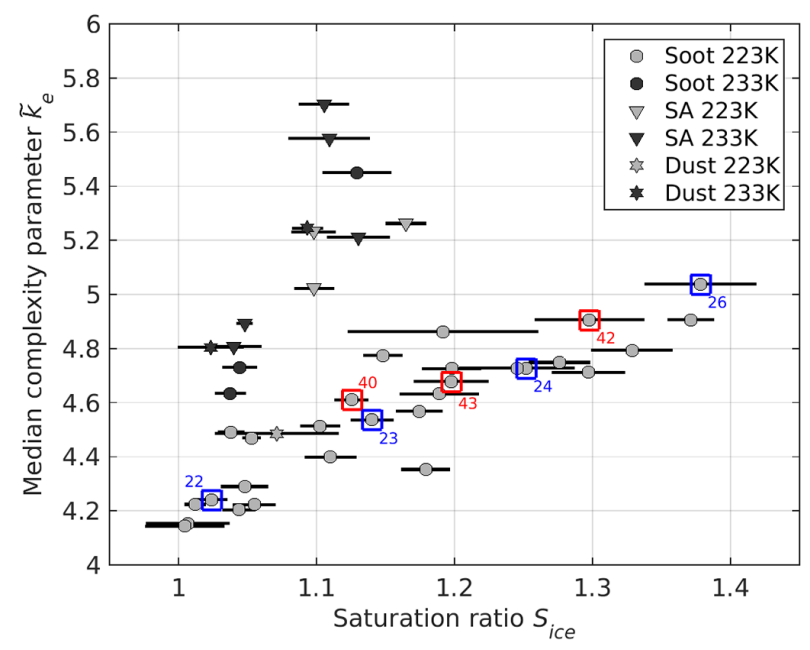

Figure 4. Median ice crystal complexity parameter $\widetilde{k_{\mathrm{e}}}$ deduced from SID-3 scattering patterns that were measured in simulated cirrus clouds at the AIDA cloud chamber. The ice clouds were grown at different ice saturation ratios $S_{\text {ice }}$ and at initial chamber temperatures of $-40^{\circ} \mathrm{C}$ (black symbols) and $-50{ }^{\circ} \mathrm{C}$ (grey symbols). Three different aerosol types were used to nucleate ice by heterogeneous nucleation on soot (circles) and mineral dust (stars) as well as by homogeneous nucleation in aqueous sulfuric acid particles (triangles).

complexity was already observed at supersaturations around $10 \%$.

\subsection{Correlation between $\widetilde{k_{\mathrm{e}}}$ and the available condensable water vapor mixing ratio $\xi_{\mathrm{v}}^{\text {acw }}$}

The previously discussed results by Bailey and Hallett (2004) as well as our own results from the optical imaging of laboratory-grown ice particles indicate that the available condensable water mass is the driving factor for the crystal growth rate and finally the crystal complexity. Although these studies do not give insight into the ice particle surface properties (except the observed (stepped) hollowness; Fig. 5), it is reasonable to assume that a high ice particle growth rate also results in the formation of surface complexity, like surface roughness and stepped hollowness. Therefore, the ice saturation ratio plotted in Fig. 4 for the -40 and $-50{ }^{\circ} \mathrm{C}$ experiments was converted into the available condensable water vapor mixing ratio $\xi_{\mathrm{v}}^{\mathrm{acw}}$ given on the $x$ axis in Fig. 6. In this approach, $\xi_{\mathrm{v}}^{\mathrm{acw}}$ was calculated as the difference between the measured interstitial water vapor mixing ratio $\xi_{\mathrm{v}}$ and the saturated mixing ratio $\xi_{\mathrm{v}}^{\mathrm{s}}$ for the given pressure and temperature conditions inside AIDA. $\xi_{\mathrm{v}}^{\mathrm{s}}$ was thereby calculated based on the parametrization of the ice vapor pressure by Murphy and Koop (2005). $\xi_{\mathrm{v}}^{\mathrm{acw}}$ therefore represents the mixing ratio of excess water molecules that can deposit to the solid ice face. This way of representing the SID-3 crystal complexity data results in a combined correlation between $\widetilde{k_{\mathrm{e}}}$ and $\xi_{\mathrm{v}}^{\mathrm{acw}}$ for the -40 and $-50^{\circ} \mathrm{C}$ experiments. Figure 6

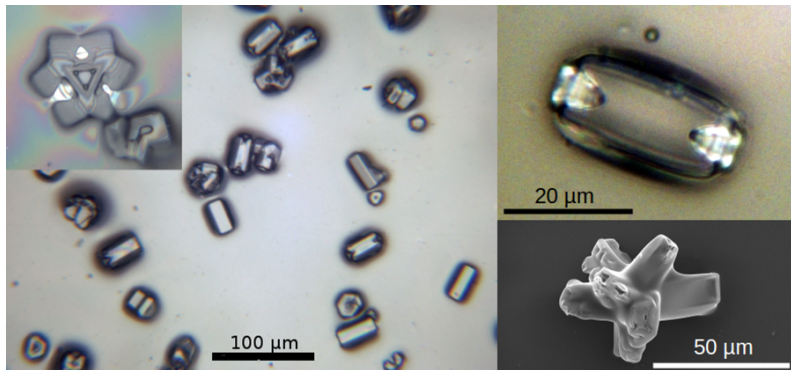

Figure 5. Ice particle replicas generated in the regrowth period of RICE01_27 at a temperature around $-55^{\circ} \mathrm{C}$ and an ice supersaturation of $19 \%$. The particle habit distribution is a mixture of solid and hollow columns as well as small rosettes (left). Hollow rosette with a maximum dimension of about $35 \mu \mathrm{m}$ (upper left). Although stepped hollowness is difficult to see with the replication method on small ice crystals, it can be identified in cases when the ice particle was ideally replicated (upper right image). Scanning electron micrograph of a rosette replica showing that in general the ice particle surface properties (including stepped hollowness) are masked by the Formvar replication method (lower right).

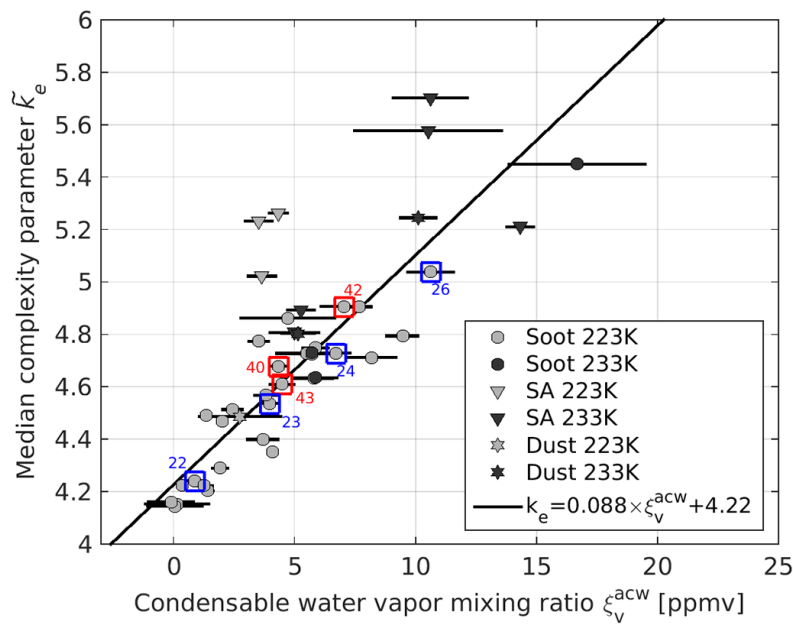

Figure 6. Median ice crystal complexity parameter $\widetilde{k_{\mathrm{e}}}$ plotted against the condensable water vapor mixing ratio that was available during the regrowth of the ice particles.

confirms the assumption that the ice crystal growth rate also controls the small-scale ice particle complexity. The correlation can be quantified by fitting a simple linear regression model to the data which gives a least square functional dependency of

$\widetilde{k_{\mathrm{e}}}=0.088 \times \xi_{\mathrm{v}}^{\mathrm{acw}}+4.22$,

with $\xi_{\mathrm{v}}^{\mathrm{acw}}$ given in ppmv.

Another conclusion that can be drawn from Figs. 4 and 6 is that the observed correlation does not depend on the type of the used aerosol or nucleation mode (homogeneous or heterogeneous), which means that the thermodynamic conditions during the ice particle (re)growth control the small- 
Table 1. Results of the particle fraction analysis for those experiments of the RICE01 and RICE03 campaign that are labeled, respectively, in blue and red in Figs. 4 and 6. All experiments where conducted at an initial temperature of $-50{ }^{\circ} \mathrm{C}$ and with soot particles as heterogeneous ice nuclei.

\begin{tabular}{ccccccc}
\hline Exp. & $S_{\text {ice }}$ & $\begin{array}{c}\xi_{\mathrm{v}}^{\text {acw }} \\
{[\mathrm{ppm}]}\end{array}$ & $\begin{array}{c}\text { Fraction of } \\
\text { rough particles }\end{array}$ & $\begin{array}{c}\text { Fraction of } \\
\text { columns }\end{array}$ & $\begin{array}{c}\text { Fraction of } \\
\text { rough columns* }\end{array}$ & $\begin{array}{c}\text { Fraction of } \\
\text { halo crystals }\end{array}$ \\
\hline \multicolumn{7}{c}{ RICE01 } \\
22 & 1.02 & 0.86 & 0.14 & 0.63 & 0.06 & 0.34 \\
23 & 1.14 & 3.97 & 0.44 & 0.65 & 0.28 & 0.39 \\
24 & 1.25 & 6.71 & 0.60 & 0.56 & 0.41 & 0.37 \\
26 & 1.38 & 10.6 & 0.84 & 0.39 & 0.73 & 0.31 \\
\hline & & & & RICE03 & & \\
\hline 40 & 1.13 & 4.48 & 0.51 & 0.58 & 0.24 & 0.41 \\
42 & 1.30 & 7.03 & 0.72 & 0.45 & 0.50 & 0.22 \\
43 & 1.20 & 4.33 & 0.55 & 0.53 & 0.28 & 0.29 \\
\hline
\end{tabular}

* Ratio of the number of rough columns to the number of all columns.

scale crystal complexity or surface roughness and not the type of ice nucleus. There is one exception, however: the regrowth experiments conducted at an initial temperature of $-50^{\circ} \mathrm{C}$ and using homogeneous nucleation in aqueous sulfuric acid particles to initiate the ice cloud (grey triangles in Fig. 6). These experiments result in higher $\widetilde{k_{\mathrm{e}}}$ values compared to the corresponding experiments with heterogeneous initial ice formation on soot (circles) or dust (stars) as well as homogeneous initial nucleation at $-40^{\circ} \mathrm{C}$ (black triangles). This indicates a "memory" effect in the ice crystal complexity for homogeneous nucleation at colder temperatures. A possible explanation for this observation could be the formation of concentrated $\mathrm{H}_{2} \mathrm{SO}_{4} / \mathrm{H}_{2} \mathrm{O}$ residuals on the ice crystal surface, which affects the regular crystal growth. Such a separation into solid ice and unfrozen residual solution was observed by calorimetric measurements on aqueous $\mathrm{H}_{2} \mathrm{SO}_{4}$ droplets in the cirrus temperature range $190<T<230 \mathrm{~K}$ (Bogdan et al., 2006; Bogdan, 2006). Although emphasized by the authors, the formation of a complete $\mathrm{H}_{2} \mathrm{SO}_{4} / \mathrm{H}_{2} \mathrm{O}$ coating of the crystal surface was not unambiguously proven by these studies. However, the formation of such coatings can have significant consequences for the ice particle growth rate and the persistence of ice supersaturations in cirrus clouds (Bogdan and Molina, 2009). Further studies with homogeneously nucleated ice particles are necessary to investigate the impact of unfrozen $\mathrm{H}_{2} \mathrm{SO}_{4} / \mathrm{H}_{2} \mathrm{O}$ residuals on the smallscale ice crystal complexity.

\subsection{Discussion of specific ice particle fractions}

Table 1 gives examples of the SID-3 pattern analysis results for the regrowth experiments labeled in blue and red in Figs. 4 and 6. The fraction of rough particles is thereby calculated by setting a threshold value $k_{\mathrm{e}}^{\text {thr }}$ of 4.6 and classifying all particles below this threshold as smooth (examples given in Fig. 1a, b) and all particles equal and above as rough (examples given in Fig. 1c, d). The fraction of columnar ice particles is calculated from a fast Fourier transformation of the polar integrated azimuthal intensity profile of the patterns according to the description given in Vochezer et al. (2016). While the fractions of rough particles and rough columns are clearly correlated with $S_{\text {ice }}$ and $\xi_{\mathrm{v}}^{\text {acw }}$, the fraction of columns stays rather constant at a value around 0.6 up to ice saturation ratios of about 1.15 followed by a significant decrease for higher supersaturations. This observation can be explained by the formation of hollow columns and rosettes at an onset saturation ratio between 1.15 and 1.2 which results in a distorted or changed symmetry in the corresponding light scattering patterns. Another result from Table 1 is the behavior of the fraction of those crystals that have indications of a $22^{\circ}$ halo in the scattering pattern. This fraction is deduced by a visual inspection of each individual valid scattering pattern for intensity spots around $22^{\circ}$ that are clearly contrasted from surrounding pixels. Interestingly, this particle fraction is not depending on $S_{\text {ice }}$ or $\xi_{\mathrm{v}}^{\text {acw }}$ but is, except for experiment 42 from RICE03, rather constant within the narrow range between 30 and $40 \%$. For the interpretation of this result one has to keep in mind that the pixels in the $22^{\circ}$ halo spot are always saturated due to the limited dynamic range of the ICCD camera of 8 bit. Therefore, the true intensity in the halo spot is unknown and, thus, it cannot be concluded from the fraction of halo particles whether and how strong a $22^{\circ}$ halo would appear in the ice cloud. Even if it is unlikely that an ice cloud with roughened ice crystals would show a halo feature, it has to be kept in mind that there is always a significant fraction of the (small) hexagonal ice columns that show the $22^{\circ}$ halo feature in the SID-3 scattering patterns also for those experiments with a very high crystal complexity. 


\subsection{Angular light scattering functions}

For the three experiments from RICE03 labeled in red in Figs. 4 and 6 and listed in Table 1, polar scattering functions were measured by the polar nephelometers PN and PHIPSHALO and are plotted in Fig. 7. The individual scattering functions given in Fig. 7 are mean values of all valid particle scattering functions measured during the regrowth periods. A valid particle scattering function has (i) an intensity above the background level for each individual angular channel and (ii) no saturated channels. Scattering functions that do not fulfil these criteria were removed from the analysis. A mean background intensity is deduced for each individual channel and is subtracted from the valid particle scattering functions before averaging. In the case of the PHIPS-HALO instrument, channel crosstalk and sensitivity characteristics are taken into consideration by applying a correction matrix to the mean scattering function. See Jourdan et al. (2003) for a description of the channel correction in the case of the PN instrument. After this, the resulting mean particle scattering function is normalized so that its integral over the instrumental angular range equals 1 .

Although there are systematic deviations in the normalized scattering functions deduced from the PN and PHIPS-HALO measurements, both instruments agree in the following observations:

i. the measured scattering functions show only minor changes from experiment to experiment

ii. the scattering functions are rather flat and featureless with no clear indications of a 22 or $46^{\circ}$ halo

iii. there are some indications of a slight ice bow-like feature in the 130 to $150^{\circ}$ angular range.

Observations (i) and (ii) can be interpreted as the result of crystal complexity that randomizes spatial light scattering to a sufficient degree so that shape-dependent features, like halo features, are removed from the polar scattering function resulting in a flat function with no significant variations for the different experiments. Interestingly, the polar scattering function is rather insensitive over a range of ice particle growth conditions where the SID-3 method still sees significant differences in the small-scale complexity parameter $\widetilde{k_{\mathrm{e}}}$ (cf. Fig. 6). Although the particle scattering functions for very low $\widetilde{k_{\mathrm{e}}}$ values have not been measured, these results might indicate that after a certain crystal complexity is induced the angular light scattering function is insensitive to further increases in this complexity. The corresponding threshold in terms of $S_{\text {ice }}$ is quite low and around 1.1 for the ice clouds grown in the $-50^{\circ} \mathrm{C}$ temperature range. In terms of the temperature-independent condensable water vapor mixing ratio $\xi_{\mathrm{v}}^{\mathrm{acw}}$, this threshold is about $4.3 \mathrm{ppmv}$. However, further analyses of the scattering functions in the different phases of the experiment runs are necessary to come to

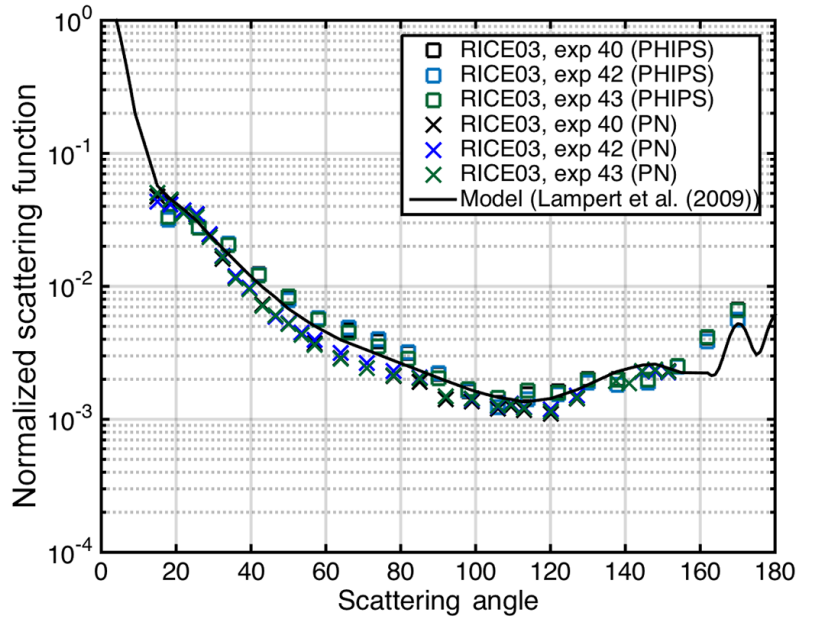

Figure 7. Mean angular scattering functions measured in the regrowth periods of those ice cloud experiments of RICE03 that are labeled in red in Figs. 4 and 6. Two polar nephelometers were deployed in these experiments: the airborne approved polar nephelometer from Clermont-Ferrand (PN, crosses) and the novel instrument PHIPS-HALO from KIT (squares).

a final conclusion on the sensitivity of the light scattering functions to the small-scale ice particle complexity.

Observation (iii) indicates a minor influence from regular or near-spherical ice crystals on the angular light scattering function of the ice clouds (Baran et al., 2012). A similar featureless scattering function with a slight indication of an ice bow-like feature was measured by the PN in a case study of a mid-level Arctic ice cloud (Lampert et al., 2009). A particle mixture composed of deeply roughened hexagonal columns and smooth ice spheres was necessary to represent this observation. The corresponding angular scattering function of this particle model has an asymmetry parameter $g$ of 0.78 and is plotted as solid line in Fig. 7. A very good agreement between the modeled and measured scattering functions is found, which is astonishing given that the modeled function is retrieved for an Arctic mid-level (not cirrus) cloud at a mean temperature of $-24.3^{\circ} \mathrm{C}$. Here, it is important to note that the measurements do not cover the forward and backward angular ranges and, therefore, also other scattering function models with different asymmetry parameters likely can fit the measurements. Further modeling work is necessary that uses the measured particle size distribution in conjunction with the shape information from the PPD-2K, SID-3 and PHIPS-HALO measurements to constrain the ice particle microphysical scheme in the iterative inversion method that was used in Lampert et al. (2009) and detailed in Oshchepkov et al. (2000) and Jourdan et al. (2003). Only such an inversion analysis would result in a more reliable model scattering function and asymmetry parameter.

However, while keeping in mind these restrictions, the good agreement of the scattering functions measured for 
laboratory-generated ice clouds in the $-50{ }^{\circ} \mathrm{C}$ temperature range with a scattering function retrieved for an Arctic midlevel cloud indicates that the above discussed small-scale complexity threshold for a rather insensitive scattering function might be of general nature and also valid for natural ice clouds. In conjunction with the main finding of our study, namely a fast developing ice particle complexity with supersaturation conditions, this indicates some important consequences for the light scattering properties of atmospheric ice particles that will be discussed in the following section.

\section{Atmospheric implications}

In the present study the ice supersaturation with temperature, i.e., the available condensable water vapor $\xi_{\mathrm{v}}^{\mathrm{acw}}$, was identified as the main driving factor for the formation of smallscale ice crystal complexity. This factor has a low threshold value of $4.3 \mathrm{ppmv}$ for the growth of ice particles with a sufficient degree of crystal complexity. A strong randomization of the light scattering is the consequence of this complexity resulting in a featureless cloud angular scattering function that is insensitive to further changes in the growth conditions. So, the question is how frequently such threshold conditions can be found in cirrus clouds in order to draw conclusions on the role of ice crystal complexity for the short-wave radiative properties of these clouds.

In a study by Krämer et al. (2009) in situ water vapor data from Arctic, midlatitude, and tropical cirrus were analyzed and discussed in terms of the frequency of supersaturated conditions inside cirrus clouds. The authors found frequency distributions of the ice saturation ratio $S_{\text {ice }}$ that are symmetrically distributed around a peak value close to 1 for the $200<T<240 \mathrm{~K}$ temperature range. Although high supersaturations up to the homogeneous freezing level were measured, information of the growth history can hardly be deduced from these data as the supersaturation quickly relaxes after a sufficient amount of ice particles have been nucleated. However, by applying a simple box model and assuming homogeneous nucleation, their modeled ice number concentrations agree well with the measured concentrations for reasonable updraft speeds indicating that the formation and growth pathway of the young cirrus particles could indeed started from high supersaturations.

In the Interhemispheric Differences in Cirrus Properties from Anthropogenic Emissions (INCA) experiment, ice saturation ratio-dependent cloud-present fractions were deduced from in situ particle measurements in northern and southern midlatitude cirrus (Ström et al., 2003). Cirrus ice particle formation onsets were estimated by the interpretation of local minima in these fractions to be a consequence of the reduced detection efficiency of the cloud particle instruments in case of recently nucleated cirrus particles. Following this interpretation, the cirrus clouds were preferentially formed in the $S_{\text {ice }}$ range between 1.4 and 1.55 and slightly be- low 1.3 for the Southern and Northern Hemisphere, respectively. It was suggested that this difference in the freezing thresholds is an effect of the different pollution levels in both hemispheres resulting in homogeneous ice nucleation as the dominant freezing mechanism in the relatively clean Southern Hemisphere and heterogeneous nucleation in the more polluted Northern Hemisphere (Haag et al., 2003). By taking into consideration that the frequency distribution of measured in-cloud temperatures during INCA was between -30 and $-60^{\circ} \mathrm{C}$ with a maximum at about $-50^{\circ} \mathrm{C}$ (Gayet et al., 2004), the ice particles nucleated and grew in an ice supersaturated environment that forces significant crystal complexity according to the chamber results shown in Fig. 4. In conjunction with the discussion of the light scattering data given in Sect. 3, it can be expected that the cirrus clouds probed during INCA should have angular scattering functions with (i) no indications of a $22^{\circ}$ halo and (ii) an asymmetry parameter $g$ with only little variations in hemispheric as well as interhemispheric comparisons. Both expectations were indeed confirmed by in situ PN measurements during INCA by Gayet et al. (2004). Based on a statistical analysis of angular scattering functions measured in the Northern and Southern Hemisphere, a very stable asymmetry parameter was deduced ranging from 0.76 to 0.78 with almost no differences in the mean values for the Northern (0.767) and Southern (0.770) Hemisphere. Only about $3 \%$ of all measured scattering functions showed a $22^{\circ}$ halo feature, also with no significant differences between the northern and southern measurements. It was concluded that the angular particle scattering properties give no indications on privileged ice nucleation mechanisms in the two hemispheres, although it was indicated from the freezing onset analysis. Here it is important to note that even though it was ruled out by the authors, the results might be partially affected by ice particle shattering on the probe tips and inlets.

In a case study of a semi-transparent midlatitude cirrus, Baran et al. (2015) analyzed angular-dependent radiometric measurements from the PARASOL satellite in order to link the shape of the back-hemispheric angular scattering function to the relative humidity $\left(\mathrm{RH}_{i}\right)$ field predicted by a numerical weather model. Even though their data set was not statistically sufficient to find a strong correlation, the authors observed the tendency that cloud regions exhibiting an ice bow feature were more associated with low $\mathrm{RH}_{i}$ values, while regions with no features in the backscattering angular scattering function were associated to $\mathrm{RH}_{i}$ values larger than about $115 \%$.

Both of the above observations are in accordance with the findings of the present paper where also no significant differences in the angular light scattering properties could be identified for growth conditions above about $S_{i}=1.1$, although significant differences in the complexity parameter $\widetilde{k_{\mathrm{e}}}$ were deduced. The cirrus clouds probed during the INCA experiments and observed in the Baran et al. (2015) case study, therefore, probably have formed in ice supersaturated con- 
ditions that were high enough to produce significant crystal complexity, irrespective of the ice nucleation mechanism. In addition to the SID-3 laboratory results, there are indications from airborne SID-3 measurements that the GLCM speckle analysis method might be sensitive to the nucleation mechanism (homogeneous or heterogeneous) in ice clouds composed of complex ice particles (Ulanowski et al., 2014).

\section{Conclusions}

In this paper the origin of small-scale ice crystal complexity and its consequences for the angular light scattering properties of cirrus clouds were investigated in specific cloud chamber experiments performed in the -40 to $-60^{\circ} \mathrm{C}$ temperature range. The particle surface complexity was deduced from highly resolved angular light scattering patterns of single ice particles measured by the latest version of the SID3. Similar to the previous work by Ulanowski et al. (2014), a speckle texture analysis was developed based on the GLCM as part of the SID-3 scattering pattern analysis package (Vochezer et al., 2016). It was found that the normalized energy feature parameter $k_{\mathrm{e}}$ of the GLCM is the most robust measure of small-scale crystal complexity. The angular light scattering function of the laboratory-generated ice clouds was measured by the two currently available airborne polar nephelometers PN and PHIPS-HALO.

A new experimental procedure was applied at the AIDA cloud chamber to regrow ice particles at defined ice saturation levels after the crystal surface properties from the initial nucleation and growth phases have been removed in a sublimation period. The nucleation of ice particles was initiated by using three different aerosol types: soot particles and mineral dust for heterogeneous ice nucleation as well as sulphuric acid particles for homogeneous nucleation. For 45 stable regrowth periods, the median crystal complexity parameter $\widetilde{k_{\mathrm{e}}}$ was deduced from the individual SID-3 scattering patterns. Averaged angular light scattering functions were deduced from the polar nephelometers for three regrowth periods.

From the experimental results the following main conclusions can be drawn.

- There is a clear correlation between the small-scale crystal complexity deduced from the SID-3 measurements and the volume mixing ratio of available condensable water vapor $\xi_{\mathrm{v}}^{\mathrm{acw}}$. The correlation could be fitted by a simple linear functional dependence given in Eq. (2).
- The small-scale particle complexity that develops during the crystal (re)growth is not influenced by the type of heterogeneous ice nucleus inside the crystal. However, there are indications for a memory effect in the case of homogeneous nucleation in aqueous sulphuric acid particles.

- There are no significant differences in the measured angular light scattering functions of ice clouds that were regrown at $\xi_{\mathrm{v}}^{\mathrm{acw}} \geqslant 4$ although significant differences in $\widetilde{k_{\mathrm{e}}}$ were deduced from the SID-3 data. This indicates threshold conditions for the small-scale particle complexity leading to an insensitive cloud scattering phase function. The measured functions are featureless and flat in the side and backward scattering directions.

These results have significant implications for the radiative transfer through cirrus clouds as water vapor measurements indicate that the growth of cirrus ice particles starts at saturation ratios that are usually above the threshold conditions for the formation of small-scale complexity. Furthermore, ice particles with a high degree of small-scale complexity can be expected if the crystals were homogeneously nucleated because (i) the growth starts at high supersaturations and (ii) there are indications that concentrated $\mathrm{H}_{2} \mathrm{SO}_{4} / \mathrm{H}_{2} \mathrm{O}$ residuals on the ice crystal surface affects further crystal growth. A prevailing ice crystal complexity in cirrus clouds would result in a low asymmetry parameter $g$ and, consequently, in a stronger solar albedo effect. The presented chamber results indicate that for typical growth condition rather low variations in $g$ are expected. However, combined in situ measurements with SID-3 and PHIPS-HALO (or PN) in cirrus clouds that were formed under different thermodynamic conditions are necessary to prove these conclusions. Such data are available from the HALO aircraft campaigns Midlatitude Cirrus (ML-CIRRUS) and Aerosol, Cloud, Precipitation, and Radiation Interactions and Dynamics of Convective Cloud Systems (ACRIDICON-CHUVA). The results of these measurements will be the subject of forthcoming publications.

\section{Data availability}

The data from this study can be obtained by contacting the corresponding author of this article. 


\section{Appendix A: Characterization of the normalized energy feature parameter $k_{\mathrm{e}}$}

The conclusion given by $\mathrm{Lu}$ et al. (2006) that $k_{\mathrm{e}}$ is the most robust GLCM feature to quantify surface roughness was checked for the SID-3 set-up by the following procedure. An analogue ice particle aggregate with severely roughened surfaces was placed on a thin polycarbonate window with anti-reflective coating. See Krasinski et al. (2007) for a description of how these ice analogue particles can be produced in the laboratory. After a visual inspection of the analogue aggregate under the optical microscope (left image of Fig. A1), the sample particle was moved into the sensitive area of SID-3 and was fixed at this position. While the instrument was forced to continuously trigger, the laser power was varied from a few milliwatts to its maximum power of $100 \mathrm{~mW}$. In this way a series of SID-3 patterns was acquired for the same particle at the same orientation but for different laser intensities (see right image of Fig. A1 for an example). The latter variation results in images with different brightnesses. In a final step, the GLCM features $k_{\mathrm{e}}$, energy, and combined roughness were statistically analyzed for different grey-level ranges. The result of this analysis is given in Table A1. The test clearly shows that $k_{\mathrm{e}}$ is the most robust GLCM feature also in the case of quantifying ice crystal complexity with SID-3.

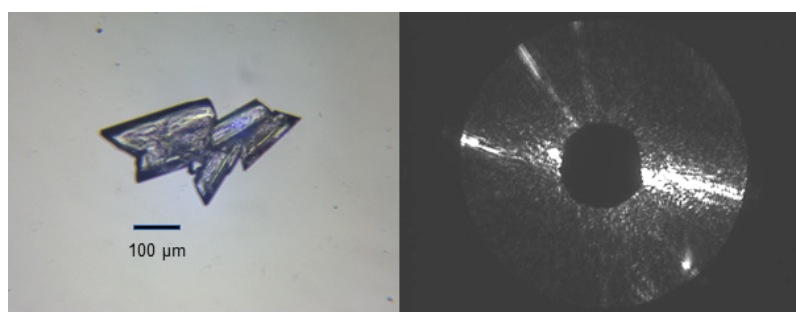

Figure A1. Microscopic image of an ice analogue aggregate with rough surface residing on a polycarbonate window (left). The sodium fluorosilicate crystals can grow to hexagonal morphologies similar to water ice crystals. The fact that their refractive index is close to water ice makes them well suited for light scattering investigations (Ulanowski et al., 2003, 2006). The crystal was moved into the sensitive area of SID-3 where scattering patterns were acquired (right).

Table A1. Relative $1 \sigma$ standard deviations of the three GLCM features $k_{\mathrm{e}}$, energy $E$, and combined roughness. The SID-3 patterns were acquired on the analogue ice particle shown in Fig. A1. The GLCM speckle texture analysis was restricted to three different grey-level ranges.

\begin{tabular}{lccc}
\hline $\begin{array}{l}\text { Grey-level } \\
\text { range }\end{array}$ & $k_{\mathrm{e}}$ & $\begin{array}{c}\text { Energy } \\
E\end{array}$ & $\begin{array}{c}\text { Combined } \\
\text { roughness }\end{array}$ \\
\hline $10-25$ & $0.66 \%$ & $1.38 \%$ & $0.95 \%$ \\
$10-50$ & $0.49 \%$ & $5.48 \%$ & $1.43 \%$ \\
$1-100$ & $0.72 \%$ & $7.77 \%$ & $1.79 \%$ \\
\hline
\end{tabular}




\section{Appendix B: Modeling SID-3 scattering patterns of deformed particles}

The problem of electromagnetic scattering is here treated through the DDA approach. We make use of the GDT-matrix code (Tricoli et al., 2015) developed to simulate the SID-3like forward scattering pattern (the electromagnetic field is calculated in an annulus between 5 and $25^{\circ}$ in the forward direction). In order to increase the upper bound of the size parameter that can be modeled, we use the publicly available code ADDA (Yurkin and Hoekstra, 2012) to calculate iteratively the inverse of the interaction matrix. The convergence is checked through comparisons of the phase functions obtained with ADDA and with Mie theory for the equivalent sphere. We find that for a refractive index of $m=1.32$, it is possible to stabilize the iterative solver in ADDA using at least 1.5 millions of dipoles (i.e., at least 10 dipoles per wavelength). In this way we are able to simulate ice particles up to a size parameter of $x=50$ (corresponding to a particle of equivalent radius of about $4 \mu \mathrm{m}$ ). Then, exploiting the equivalence of the transition matrix with the inverse of the interaction matrix, we import this matrix into the GDT-matrix code in order to reproduce the output format required for the SID-3 analysis algorithm. In fact, the square modulus of the electric field is calculated for the given forward scattering annulus and it is then plotted on a plane of $780 \times 582$ pixels. The simulated wavelength corresponds to the SID-3 laser beam, i.e., $532 \mathrm{~nm}$. In order to be able to apply the GLCM method, the output intensity plot is saved as 8 bit grey-scale JPEG files. The mean intensity of the generated JPEG pictures is then rescaled to 20 (in order to be comparable with the brightness range restrictions used in the analysis as described in Sect. 2.1.2). We apply this method to deformed spherical particles. These shapes are generated through the publicly available software called Siris, described in Muinonen et al. (1996) and freely available from Muinonen and Nousiainen (2003). To reproduce shapes like the one depicted in Fig. 5 (lower right corner) we chose a power law description of the correlation function. The power law index for the correlation coefficient is set to 3 . We chose a minimum polynomial order of 2 and a maximum of 10 (for larger minima the shape has more small-scale deformations). Then we vary the relative standard deviation of the radial distance $(\sigma)$ from 0.02 to 0.5 . The generated shapes are represented in Fig. B1 (all simulated intensity patterns are calculated for a fixed size parameter of $x=46$ ).

It is clearly seen that for small $\sigma$ the simulated SID-3 patterns show only slight deviations from the regular concentric rings expected from diffraction theory for a smooth sphere. In contrast, for large deformations (e.g., $\sigma=0.3$ ) the patterns show speckles. The larger $\sigma$ the smaller the speckle intensity spots in the pattern. The same is also observed for a fixed

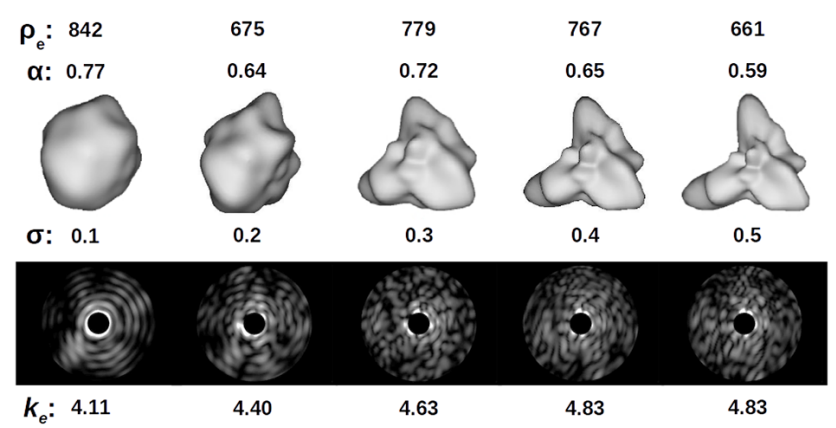

Figure B1. Distorted spherical ice model particles with different deformation parameters $\sigma$, effective densities $\rho_{\mathrm{e}}$, and area ratios $\alpha$ that were used in the ADDA/GDT-matrix approach (upper panel). All input model particles have a fixed size parameter of 46 . Corresponding 8 bit grey-scale output patterns (lower panel). The $k_{\mathrm{e}}$ values of the GLCM analysis are given below each pattern.

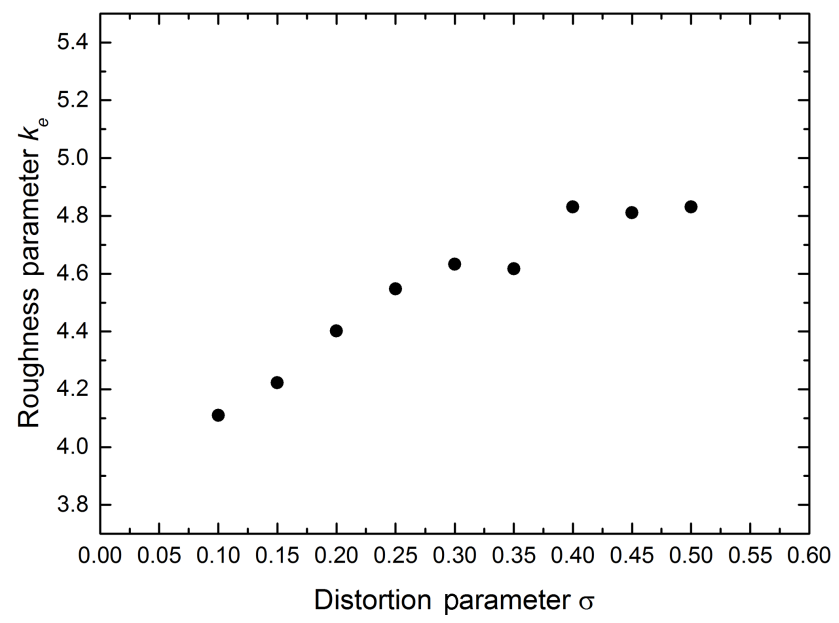

Figure B2. Dependence of the crystal complexity parameter $k_{\mathrm{e}}$ on the distortion parameter $\sigma$ for the model particles shown in Fig. B1.

$\sigma$ and increasing size parameter (not shown). Thus, $\sigma$ represents a microphysical shape parameter used to describe the degree of deformation (relative to the smooth sphere). Interestingly, by applying the GLCM method to the simulated patterns, the relative standard deviation of the radial distance $(\sigma)$ can be related to the normalized energy feature parameter $k_{\mathrm{e}}$ (see Fig. B2). A linear relation is obtained between $\sigma$ and $k_{\mathrm{e}}$ up to deformations of about $\sigma=0.5$ where $k_{\mathrm{e}}$ starts to saturate. Although Fig. B2 shows a clear correlation, more such calculations are necessary to investigate the dependence of $k_{\mathrm{e}}$ on the small-scale complexity of faceted ice crystals. It is envisaged to do these calculations in future with the goal to develop a calibration of the small-scale crystal complexity parameter $k_{\mathrm{e}}$ against the physical ice crystal surface roughness. 


\section{Appendix C: Growth rate analysis}

In RICE01, the ice particle morphological parameters and their frequencies of occurrence have been measured by the PHIPS imager as functions of temperature, ice saturation ratio $\left(S_{\text {ice }}\right)$, and pressure. Figure $\mathrm{C} 1$ shows an example result for the regrowth experiment RICE01_27 started at an initial temperature of $-50^{\circ} \mathrm{C}$. Figure $\mathrm{C} 1$ a shows the pressure and temperature inside AIDA during the expansion. The ice saturation ratio $S_{\text {ice }}$ is presented in Fig. C1b, and Fig. C1c gives the evolution of the particle equivalent diameter during the initial growth (I) and the regrowth (II) phases of the experiment. The AIDA atmospheric conditions forced the generation of two main habit types (compact particles and columns) which could be classified by the imaging system of PHIPS-HALO as well as the replicator strip analysis (Fig. 5). The temporal evolution of the particle equivalent diameters shows quasi-linear increases of the particle dimension during the phases of near-constant ice supersaturation conditions (indicated in yellow in Fig. C1). These periods were later used to calculate the particle growth rate. The regrowth at $S_{\text {ice }} \approx 1.2$ (phase II) resulted in the formation of hollow columns that were observed in this phase (sample images in Figs. C1 as well as 5). In other experiments at higher $S_{\text {ice, }}$, even more complex deformations were observed due to the fast growth of the crystals. Finally, Fig. C1d shows the fraction of columnar particles deduced from the PHIPSHALO images. It shows that the column fraction increased with time, which is due to a size-dependent shape classification for particles in this size range. However, at the final stage of phase II, a column fraction of 0.4 to 0.5 was deduced, which is close to 0.58 inferred from the SID-3 patterns analysis. After phase II, there is a period (starting at $1500 \mathrm{~s}$ ) where the temperature increased and $S_{\text {ice }}$ decreased. At this stage the particles started to sublimate at ice subsaturated conditions, resulting in the formation of rounded particle edges that could be clearly observed in the PHIPS-HALO images of the columnar ice crystals in this stage (see images in Figs. C1c and 3). Interestingly, the sublimation process results in a scatter of the deduced column fraction in Fig. C1d.

Along a series of AIDA expansions during RICE01, dif-

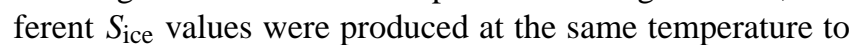
study the influence of $S_{\text {ice }}$ on the particle growth rate at constant temperature. The $S_{\text {ice }}$ value was kept constant for certain time in each expansion to allow sufficient crystal growth. The growth rates of the $c$ axis, $a$ axis, and equivalent diameter of the columnar ice particles were deduced for four different $S_{\text {ice }}$ regrowth experiments conducted at the same temperature $\left(-56^{\circ} \mathrm{C}\right)$. The results are shown in Fig. C2. In agreement with the results from Bailey and Hallett (2004), the growth rates correlate with the ice supersaturation. However, Bailey and Hallett (2004) deduced a linear dependence of the maximum particle dimension with supersaturation while our results rather indicate an exponential dependence. This can be attributed to the different experimental procedures ap-

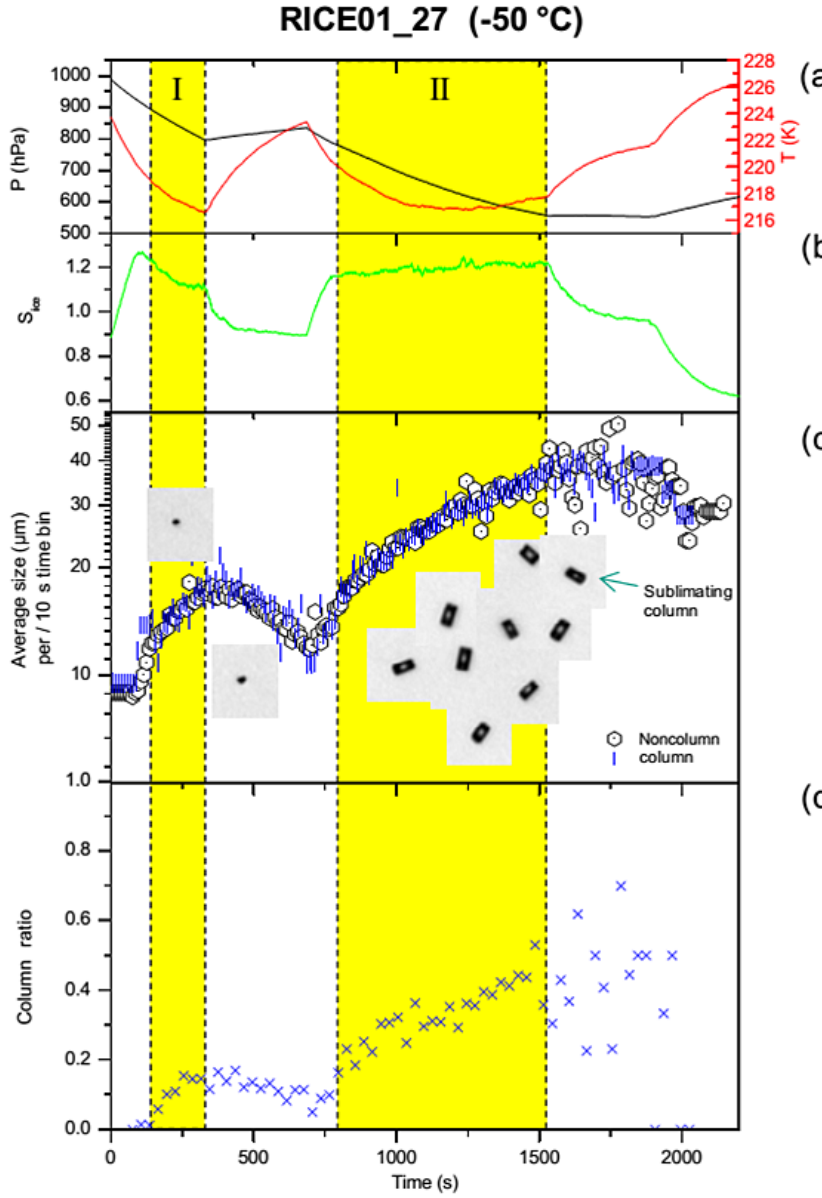

Figure C1. Temporal evolution of the AIDA cirrus cloud experiment RICE01_27. (a) Gas temperature and pressure inside the AIDA chamber. (b) Ice saturation ratio $S_{\text {ice }}$ inside the AIDA volume. (c) Geometric particle diameters as measured by PHIPSHALO. (d) Column ratio during the experiment.

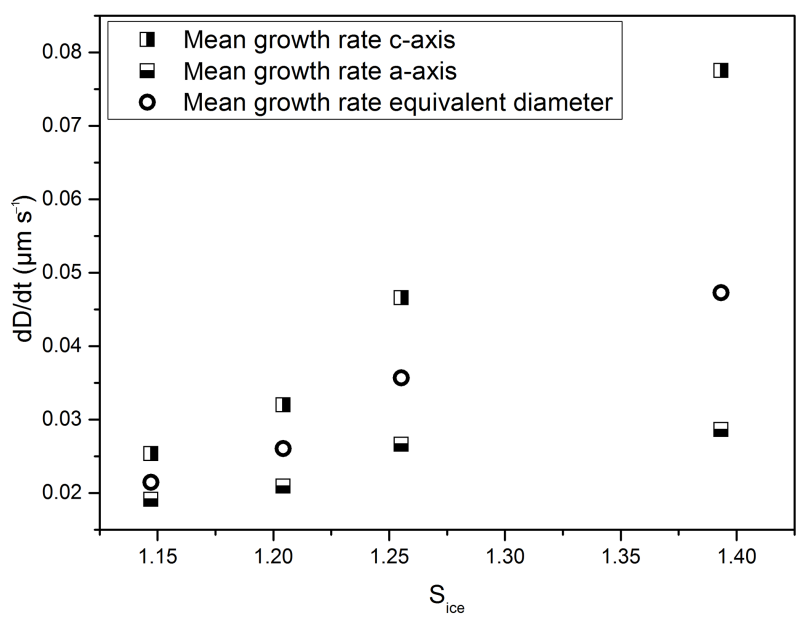

Figure C2. Growth rates of the $c$ axis, $a$ axis, and equivalent diameter of columnar ice particles deduced for four different $S_{\text {ice }}$ regrowth experiments. The regrowth periods were conducted at the same temperature of $-56{ }^{\circ} \mathrm{C}$. 
plied in the two studies. While in the case of Bailey and Hallett (2004), the crystals were nucleated and grown on a glass wire, the ice particles were nucleated and grown in airborne state in the AIDA cloud chamber, which mimics the formation and growth under natural conditions. It is also noticed that the $c$ axis grows faster than the $a$ axis of the columnar ice particles. However, the $c$ axis growth rate of $0.047 \mu \mathrm{m} \mathrm{s}^{-1}$ deduced for $S_{\text {ice }}=1.26$ lies within the range given by Bailey and Hallett (2012) for this saturation ratio. 
Acknowledgements. The authors are grateful to all members of the AIDA staff for their continuous support during the chamber experiments. Alexei Kiselev is thanked for producing electron micrographs of ice particle replicas. This work was funded in part by KIT, the German Helmholtz Association, through its research program "Atmosphere and Climate (ATMO)", as well as by the German Research Foundation (DFG) within the HALO priority program 1294 (contract SCHN 1140/1-2) and the research grant SCHN 1140/2-1. The LaMP group would like to acknowledge the EECLAT project (Expecting EarthCare, Learning from A-Train) supported by the French Centre National des Études Spatiales (CNES).

The article processing charges for this open-access

publication were covered by a Research

Centre of the Helmholtz Association.

Edited by: D. Knopf

\section{References}

Abdelmonem, A., Schnaiter, M., Amsler, P., Hesse, E., Meyer, J., and Leisner, T.: First correlated measurements of the shape and light scattering properties of cloud particles using the new Particle Habit Imaging and Polar Scattering (PHIPS) probe, Atmos. Meas. Tech., 4, 2125-2142, doi:10.5194/amt-4-2125-2011, 2011.

Abdelmonem, A., Järvinen, E., Duft, D., Hirst, E., Vogt, S., Leisner, T., and Schnaiter, M.: PHIPS-HALO: The airborne Particle Habit Imaging and Polar Scattering probe. Part I: Design and Operation, Atmos. Meas. Tech. Discuss., doi:10.5194/amt-2016-42, in review, 2016.

Bailey, M. and Hallett, J.: Growth rates and habits of ice crystals between $-20^{\circ} \mathrm{C}$ and $-70^{\circ} \mathrm{C}$, J. Atmos. Sci., 61, 514-544, 2004.

Bailey, M. and Hallett, J.: Ice crystal linear growth rates from -20 degrees to -70 degrees $\mathrm{C}$ : confirmation from wave cloud studies, J. Atmos. Sci., 69, 390-402, 2012.

Baran, A. J.: A review of the light scattering properties of cirrus, J. Quant. Spectrosc. Ra., 110, 1239-1260, doi:10.1016/j.jqsrt.2009.02.026, 2009.

Baran, A. J.: From the single-scattering properties of ice crystals to climate prediction: a way forward, Atmos. Res., 112, 45-69, doi:10.1016/j.atmosres.2012.04.010, 2012.

Baran, A. J. and Francis, P. N.: On the radiative properties of cirrus cloud at solar and thermal wavelengths: A test of model consistency using high-resolution airborne radiance measurements, Q. J. Roy. Meteor. Soc., 130, 763-778, doi:10.1256/qj.03.151, 2004.

Baran, A. J., Havemann, S., Francis, P. N., and Watts, P. D.: A consistent set of single-scattering properties for cirrus cloud: tests using radiance measurements from a dual-viewing multiwavelength satellite-based instrument, J. Quant. Spectrosc. Ra., 79-80, 549-567, doi:10.1016/S0022-4073(02)00307-2, 2003.

Baran, A. J., Gayet, J.-F., and Shcherbakov, V.: On the interpretation of an unusual in-situ measured ice crystal scattering phase function, Atmos. Chem. Phys., 12, 9355-9364, doi:10.5194/acp12-9355-2012, 2012.
Baran, A. J., Hill, P., Furtado, K., Field, P., and Manners, J.: A Coupled Cloud Physics-Radiation Parameterization of the Bulk Optical Properties of Cirrus and Its Impact on the Met Office Unified Model Global Atmosphere 5.0 Configuration, J. Climate, 27, 7725-7752, doi:10.1175/JCLI-D-13-00700.1, 2014a.

Baran, A. J., Cotton, R., Furtado, K., Havemann, S., Labonnote, L.-C., Marenco, F., Smith, A., and Thelen, J.-C.: A self-consistent scatteringmodel for cirrus. II: The high and low frequencies, Q. J. Roy. Meteor. Soc., 140, 1039-1057, doi:10.1002/qj.2193, 2014b.

Baran, A. J., Furtado, K., Labonnote, L.-C., Havemann, S., Thelen, J.-C., and Marenco, F.: On the relationship between the scattering phase function of cirrus and the atmospheric state, Atmos. Chem. Phys., 15, 1105-1127, doi:10.5194/acp-15-1105-2015, 2015.

Baum, B. A., Yang, P., Heymsfield, A. J., Schmitt, C. G., Xie, Y., Bansemer, A., Hu, Y. X., and Zhang, Z. B.: Improvements in shortwave bulk scattering and absorption models for the remote sensing of ice clouds, J. Appl. Meteorol. Clim., 50, 1037-1056, 2011.

Bogdan, A.: Reversible formation of glassy water in slowly cooling diluted drops, J. Phys. Chem. B, 110, 12205-12206, doi:10.1021/jp062464a, 2006.

Bogdan, A. and Molina, M. J.: Why does large relative humidity with respect to ice persist in cirrus ice clouds?, J. Phys. Chem. A, 113, 14123-14130, 2009.

Bogdan, A., Molina, M. J., Sassen, K., and Kulmala, M.: Formation of low-temperature cirrus from $\mathrm{H}_{2} \mathrm{SO}_{4} / \mathrm{H}_{2} \mathrm{O}$ aerosol droplets, J. Phys. Chem. A, 110, 12541-12542, doi:10.1029/2003GL017034, 2006.

Cole, B. H., Yang, P., Baum, B. A., Riedi, J., and C.-Labonnote, L.: Ice particle habit and surface roughness derived from PARASOL polarization measurements, Atmos. Chem. Phys., 14, 37393750, doi:10.5194/acp-14-3739-2014, 2014.

Cotton, R., Osborne, S., Ulanowski, Z., Hirst, E., Kaye, P. H., and Greenaway, R. S.: The ability of the Small Ice Detector (SID-2) to characterize cloud particle and aerosol morphologies obtained during flights of the FAAM BAe-146 research aircraft, J. Atmos. Ocean. Tech., 27, 290-303, doi:10.1175/2009jtecha1282.1, 2010.

Crépel, O., Gayet, J.-F., Fournol, J.-F., and Oshchepkov, S.: A new airborne Polar Nephelometer for the measurement of optical and microphysical cloud properties. Part II: Preliminary tests, Ann. Geophys., 15, 460-470, doi:10.1007/s00585-997-0460-0, 1997.

Ebert, V., Teichert, H., Giesemann, C., Saathoff, H., and Schurath, U.: Fibre-coupled in-situ laser absorption spectrometer for the selective detection of water vapour traces down to the ppblevel, Tech. Mess., 72, 23-30, doi:10.1524/teme.72.1.23.56689, 2005.

Fahey, D. W., Gao, R.-S., Möhler, O., Saathoff, H., Schiller, C., Ebert, V., Krämer, M., Peter, T., Amarouche, N., Avallone, L. M., Bauer, R., Bozóki, Z., Christensen, L. E., Davis, S. M., Durry, G., Dyroff, C., Herman, R. L., Hunsmann, S., Khaykin, S. M., Mackrodt, P., Meyer, J., Smith, J. B., Spelten, N., Troy, R. F., Vömel, H., Wagner, S., and Wienhold, F. G.: The AquaVIT-1 intercomparison of atmospheric water vapor measurement techniques, Atmos. Meas. Tech., 7, 3177-3213, doi:10.5194/amt-7-3177-2014, 2014.

Febvre, G., Gayet, J.-F., Minikin, A., Schlager, H., Shcherbakov, V., Jourdan, O., Busen, R., Fiebig, M., Kärcher, B., and 
Schumann, U.: On optical and microphysical characteristics of contrails and cirrus, J. Geophys. Res., 114, D02204, doi:10.1029/2008JD010184, 2009.

Field, P. R., Baran, A. J., Kaye, P. H., Hirst, E., and Greenaway, R.: A test of cirrus ice crystal scattering phase functions, Geophys. Res. Lett., 30, 1752-1755, doi:10.1029/2003GL017482, 2003.

Gayet, J. F., Crépel, O., Fournol, J. F., and Oshchepkov, S.: A new airborne polar Nephelometer for the measurements of optical and microphysical cloud properties. Part I: Theoretical design, Ann. Geophys., 15, 451-459, doi:10.1007/s00585-997-0451-1, 1997.

Gayet, J.-F., Auriol, F., Oshchepkov, S., Schroder, F., Duroure, C., Febvre, G., Fournol, J.-F., Crepel, O., Personne, P., and Daugereon, D.: In situ measurements of the scattering phase function of stratocumulus, contrails and cirrus, Geophys. Res. Lett., 25, 971-974, doi:10.1029/98GL00541, 1998.

Gayet, J. F., Ovarlez, J., Shcherbakov, V., Ström, J., Schumann, U., Minikin, A., Auriol, F., Petzold, A., and Monier, M.: Cirrus cloud microphysical and optical properties at southern and northern midlatitudes during the INCA experiment, J. Geophys. Res.Atmos., 109, 1-13, doi:10.1029/2004JD004803, 2004.

Guignard, A., Stubenrauch, C. J., Baran, A. J., and Armante, R.: Bulk microphysical properties of semi-transparent cirrus from AIRS: a six year global climatology and statistical analysis in synergy with geometrical profiling data from CloudSatCALIPSO, Atmos. Chem. Phys., 12, 503-525, doi:10.5194/acp12-503-2012, 2012.

Haag, W., Kärcher, B., Ström, J., Minikin, A., Lohmann, U., Ovarlez, J., and Stohl, A.: Freezing thresholds and cirrus cloud formation mechanisms inferred from in situ measurements of relative humidity, Atmos. Chem. Phys., 3, 1791-1806, doi:10.5194/acp3-1791-2003, 2003.

Haralick, R. M., Shanmugam, K., and Dinstein, I.: Textural features for image classification, IEEE T. Syst. Man Cyb., SMC-3, 610 621, doi:10.1109/TSMC.1973.4309314, 1973.

Hirst, E., Kaye, P. H., Greenaway, R. S., Field, P., and Johnson, D. W.: Discrimination of micrometre-sized ice and supercooled droplets in mixed-phase cloud, Atmos. Environ., 35, 33 47, doi:10.1016/S1352-2310(00)00377-0, 2001.

Järvinen, E., Vochezer, P., Möhler, O., and Schnaiter, M.: Laboratory study of microphysical and scattering properties of coronaproducing cirrus clouds, Appl. Optics, 53, 7566-7575, 2014.

Johnson, A., Lasher-Trapp, S., Bansemer, A., Ulanowski, Z., and Heymsfield, A. J.: Difficulties in early ice detection with the Small Ice Detector-2 HIAPER (SID-2H) in maritime cumuli, J. Atmos. Ocean. Tech., 31, 1263-1275, doi:10.1175/JTECH-D13-00079.1, 2014.

Jourdan, O., Oshchepkov, S., and Gayet, J.-F.: Statistical analysis of cloud light scattering and microphysical properties obtained from airborne measurements, J. Geophys. Res., 108, 4155, doi:10.1029/2002JD002723, 2003.

Jourdan, O., Mioche, G., Garrett, T. J., Schwarzenböck, A., Vidot, J., Xie, Y., Shcherbakov, V., Yang, P., and Gayet, J. F.: Coupling of the microphysical and optical properties of an Arctic nimbostratus cloud during the ASTAR 2004 experiment: implications for light-scattering modeling, J. Geophys. Res.-Atmos., 115, D23206, doi:10.1029/2010JD014016, 2010.

Krasinski, M. J., Krasinska, K. R., and Ulanowski, Z.: Investigation of growth kinetics and morphology of sodium fluorosilicate ice- analogue crystals in solutions and gels, Cryst. Res. Technol., 42, 1237-1242, 2007.

Lampert, A., Ehrlich, A., Dörnbrack, A., Jourdan, O., Gayet, J.F., Mioche, G., Shcherbakov, V., Ritter, C., and Wendisch, M.: Microphysical and radiative characterization of a subvisible midlevel Arctic ice cloud by airborne observations - a case study, Atmos. Chem. Phys., 9, 2647-2661, doi:10.5194/acp-9-26472009, 2009.

Liu, C., Yang, P., Minnis, P., Loeb, N., Kato, S., Heymsfield, A., and Schmitt, C.: A two-habit model for the microphysical and optical properties of ice clouds, Atmos. Chem. Phys., 14, 13719-13737, doi:10.5194/acp-14-13719-2014, 2014.

Lu, R.-S., Tian, G.-Y., Gledhill, D., and Ward, S.: Grinding surface roughness measurement based on the co-occurrence matrix of speckle pattern texture, Appl. Optics, 45, 8839, doi:10.1364/ao.45.008839, 2006.

Magee, N. B., Miller, A., Amaral, M., and Cumiskey, A.: Mesoscopic surface roughness of ice crystals pervasive across a wide range of ice crystal conditions, Atmos. Chem. Phys., 14, 12357 12371, doi:10.5194/acp-14-12357-2014, 2014.

Miloshevich, L. M. and Heymsfield, A. J.: A balloon-borne continuous cloud particle replicator for measuring vertical profiles, of cloud microphysical properties: instrument design, performance, and collection efficiency analysis, J. Atmos. Ocean. Tech., 14, 753-768, doi:10.1175/15200426(1997)014<0753:ABBCCP>2.0.CO;2, 1997.

Mitchell, D., L., Rasch, P., Ivanova, D., McFarquhar, G., and Nousiainen, T.: Impact of small ice crystal assumptions on ice sedimentation rates in cirrus clouds and GCM simulations, Geophys. Res. Lett., 35, L09806, doi:10.1029/2008GL033552, 2008.

Möhler, O., Büttner, S., Linke, C., Schnaiter, M., Saathoff, H., Stetzer, O., Wagner, R., Krämer, M., Mangold, A., Ebert, V., and Schurath, U.: Effect of sulfuric acid coating on heterogeneous ice nucleation by soot aerosol particles, J. Geophys. Res., 110, D11210, doi:10.1029/2004jd005169, 2005a.

Möhler, O., Linke, C., Saathoff, H., Schnaiter, M., Wagner, R., Mangold, A., Krämer, M., and Schurath, U.: Ice nucleation on flame soot aerosol of different organic carbon content, Meteorol. Z., 14, 477-484, 2005b.

Möhler, O., Field, P. R., Connolly, P., Benz, S., Saathoff, H., Schnaiter, M., Wagner, R., Cotton, R., Krämer, M., Mangold, A., and Heymsfield, A. J.: Efficiency of the deposition mode ice nucleation on mineral dust particles, Atmos. Chem. Phys., 6, 30073021, doi:10.5194/acp-6-3007-2006, 2006.

Muinonen, K. and Nousiainen, T.: Free software for light scattering by small particles, available at: https://wiki.helsinki.fi/display/ PSR/SIRIS (last access: 3 November 2015), 2003.

Muinonen, K., Nousiainen, T., Fast, P., Lumme, K., and Peltoniemi, J. I.: Light scattering by Gaussian random particles: ray optics approximation, J. Quant. Spectrosc. Ra., 55, 577-601, doi:10.1016/0022-4073(96)00003-9, 1996.

Murphy, D. M. and Koop, T.: Review of the vapour pressures of ice and supercooled water for atmospheric applications, Q. J. Roy. Meteor. Soc., 131, 1539-1565, doi:10.1256/qj.04.94, 2005.

Neshyba, S. P., Lowen, B., Benning, M., Lawson, A., and Rowe, P. M.: Roughness metrics of prismatic facets of ice, J. Geophys. Res., 118, 3309-3318, 2013.

Oshchepkov, S., Isaka, H., Gayet, J.-F., Sinyuk, A., Auriol, F., and Havemann, S.: Microphysical properties of mixed-phase \& 
ice clouds retrieved from in situ airborne "Polar Nephelometer" measurement, Geophys. Res. Lett., 27, 209-212, 2000.

Pfalzgraff, W. C., Hulscher, R. M., and Neshyba, S. P.: Scanning electron microscopy and molecular dynamics of surfaces of growing and ablating hexagonal ice crystals, Atmos. Chem. Phys., 10, 2927-2935, doi:10.5194/acp-10-2927-2010, 2010.

Schmitt, C. G. and Heymsfield, A. J.: Observational quantification of the separation of simple and complex atmospheric ice particles, Geophys. Res. Lett., 41, 1301-1307, doi:10.1002/2013GL058781, 2014.

Schnaiter, M., Kaye, P. H., Hirst, E., Ulanowski, Z., and Wagner, R.: Exploring the surface roughness of small ice crystals by measuring high resolution angular scattering patterns, AAPP, Phys. Math. Nat. Sci., 89, C1V89S1P084, doi:10.1478/C1V89S1P084, 2011.

Schnaiter, M., Büttner, S., Möhler, O., Skrotzki, J., Vragel, M., and Wagner, R.: Influence of particle size and shape on the backscattering linear depolarisation ratio of small ice crystals - cloud chamber measurements in the context of contrail and cirrus microphysics, Atmos. Chem. Phys., 12, 10465-10484, doi:10.5194/acp-12-10465-2012, 2012.

Schön, R., Schnaiter, M., Ulanowski, Z., Schmitt, C., Benz, S., Möhler, O., Vogt, S., Wagner, R., and Schurath, U.: Particle habit imaging using incoherent light: a first step toward a novel instrument for cloud microphysics, J. Atmos. Ocean. Tech., 28, 493$512,2011$.

Seifert, M., Tiede, R., Schnaiter, M., Linke, C., Mohler, O., Schurath, U., and Strom, J.: Operation and performance of a differential mobility particle sizer and a TSI 3010 condensation particle counter at stratospheric temperatures and pressures, J. Aerosol Sci., 35, 981-993, 2004.

Ström, J., Seifert, M., Kärcher, B., Ovarlez, J., Minikin, A., Gayet, J.-F., Krejci, R., Petzold, A., Auriol, F., Haag, W., Busen, R., Schumann, U., and Hansson, H. C.: Cirrus cloud occurrence as function of ambient relative humidity: a comparison of observations obtained during the INCA experiment, Atmos. Chem. Phys., 3, 1807-1816, doi:10.5194/acp-3-1807-2003, 2003.

Takahashi, T. and Fukuta, N.: Ice crystal replication with common plastic solutions, J. Atmos. Ocean. Tech., 5, 129-135, doi:10.1175/1520-0426(1988)005<0129:ICRWCP>2.0.CO;2, 1988.

Tricoli, U., Vochezer, P., and Pfeilsticker, K.: Transition operator calculation with Green's dyadic technique for electromagnetic scattering: a numerical approach using the Dyson equation, J. Quant. Spectrosc. Ra., 162, 77-88, doi:10.1016/j.jqsrt.2015.04.006, 2015.

Ulanowski, Z., Hesse, E., Kaye, P. H., Baran, A. J., and Chandrasekhar, R.: Scattering of light from atmospheric ice analogues, J. Quant. Spectrosc. Ra., 79, 1091-1102, 2003.

Ulanowski, Z., Hesse, E., Kaye, P. H., and Baran, A. J.: Light scattering by complex ice-analogue crystals, J. Quant. Spectrosc. Ra., 100, 382-392, 2006.

Ulanowski, Z., Kaye, P. H., Hirst, E., and Greenaway, R.: Light scattering by ice particles in the Earth's atmosphere and related laboratory measurements, in: Electromagn. Light Scatt. XII, Conf. Proceedings, edited by: Muinonen, K., Penttilä, A., Lindqvist, H., Nousiainen, T., and Videen, G., 28 June-2 July 2010, Univ. Helsinki, Finl., 294-297, 2010.
Ulanowski, Z., Kaye, P. H., Hirst, E., Greenaway, R. S., Cotton, R. J., Hesse, E., and Collier, C. T.: Incidence of rough and irregular atmospheric ice particles from Small Ice Detector 3 measurements, Atmos. Chem. Phys., 14, 1649-1662, doi:10.5194/acp14-1649-2014, 2014.

van Diedenhoven, B., Cairns, B., Fridlind, A. M., Ackerman, A. S., and Garrett, T. J.: Remote sensing of ice crystal asymmetry parameter using multi-directional polarization measurements Part 2: Application to the Research Scanning Polarimeter, Atmos. Chem. Phys., 13, 3185-3203, doi:10.5194/acp-13-31852013, 2013.

Vochezer, P., Järvinen, E., Wagner, R., Kupiszewski, P., Leisner, T., and Schnaiter, M.: In situ characterization of mixed phase clouds using the Small Ice Detector and the Particle Phase Discriminator, Atmos. Meas. Tech., 9, 159-177, doi:10.5194/amt-9-1592016, 2016.

Wagner, R., Bunz, H., Linke, C., Möhler, O., Naumann, K. H., Saathoff, H., Schnaiter, M., and Schurath, U.: Chamber simulations of cloud chemistry: the AIDA Chamber, in: NATO Adv. Res. Work. Environ. Simul. Chambers Appl. to Atmos. Chem. Process. (2004 Zakopane, Poland), edited by: Barnes, I. and Rudzinski, K. J., Springer, Dordrecht, the Netherlands, 2006.

Wagner, R., Benz, S., Bunz, H., Möhler, O., Saathoff, H., Schnaiter, M., Leisner, T., and Ebert, V.: Infrared optical constants of highly diluted sulfuric acid solution droplets at cirrus temperatures, J. Phys. Chem. A, 112, 11661-11676, 2008.

Wagner, R., Möhler, O., Saathoff, H., Schnaiter, M., and Leisner, T.: High variability of the heterogeneous ice nucleation potential of oxalic acid dihydrate and sodium oxalate, Atmos. Chem. Phys., 10, 7617-7641, doi:10.5194/acp-10-7617-2010, 2010.

Wagner, R., Höhler, K., Möhler, O., Saathoff, H., and Schnaiter, M.: Crystallization and immersion freezing ability of oxalic and succinic acid in multi-component aqueous organic aerosol particles, Geophys. Res. Lett., 42, 2464-2472, doi:10.1002/2015GL063075, 2015.

Yang, H., Dobbie, S., Herbert, R., Connolly, P., Gallagher, M., Ghosh, S., Al-Jumur, S. M. R. K., and Clayton, J.: The effect of observed vertical structure, habits, and size distributions on the solar radiative properties and cloud evolution of cirrus clouds, Q. J. Roy. Meteor. Soc., 138, 1221-1232, doi:10.1002/qj.973, 2012.

Yang, P., Liou, K.-N., Bi, L., Liu, C., Yi, B., and Baum, B. A.: On the radiative properties of ice clouds: Light scattering, remote sensing, and radiation parameterization, Adv. Atmos. Sci., 32, 32-63, doi:10.1007/s00376-014-0011-z, 2015.

Yi, B., Yang, P., Baum, B. A., L'Ecuyer, T., Oreopoulos, L., Mlawer, E. J., Heymsfield, A. J., and Liou, K.-N.: Influence of ice particle surface roughening on the global cloud radiative effect, J. Atmos. Sci., 70, 2794-2807, doi:10.1175/JAS-D-13020.1, 2013.

Yurkin, M. and Hoekstra, A.: User manual for the discrete dipole approximation code ADDA 1.1, available at: http:// a-dda.googlecode.com/svn/tags/rel_1.1/doc/manual.pdf (last access: 3 November 2015), 2012.

Zhang, Y., Macke, A., and Albers, F.: Effect of crystal size spectrum and crystal shape on stratiform cirrus radiative forcing, Atmos. Res., 52, 59-75, 1999. 